\title{
Opportunities for Energy Efficiency Improvements in the U.S. Electricity Transmission and Distribution System
}

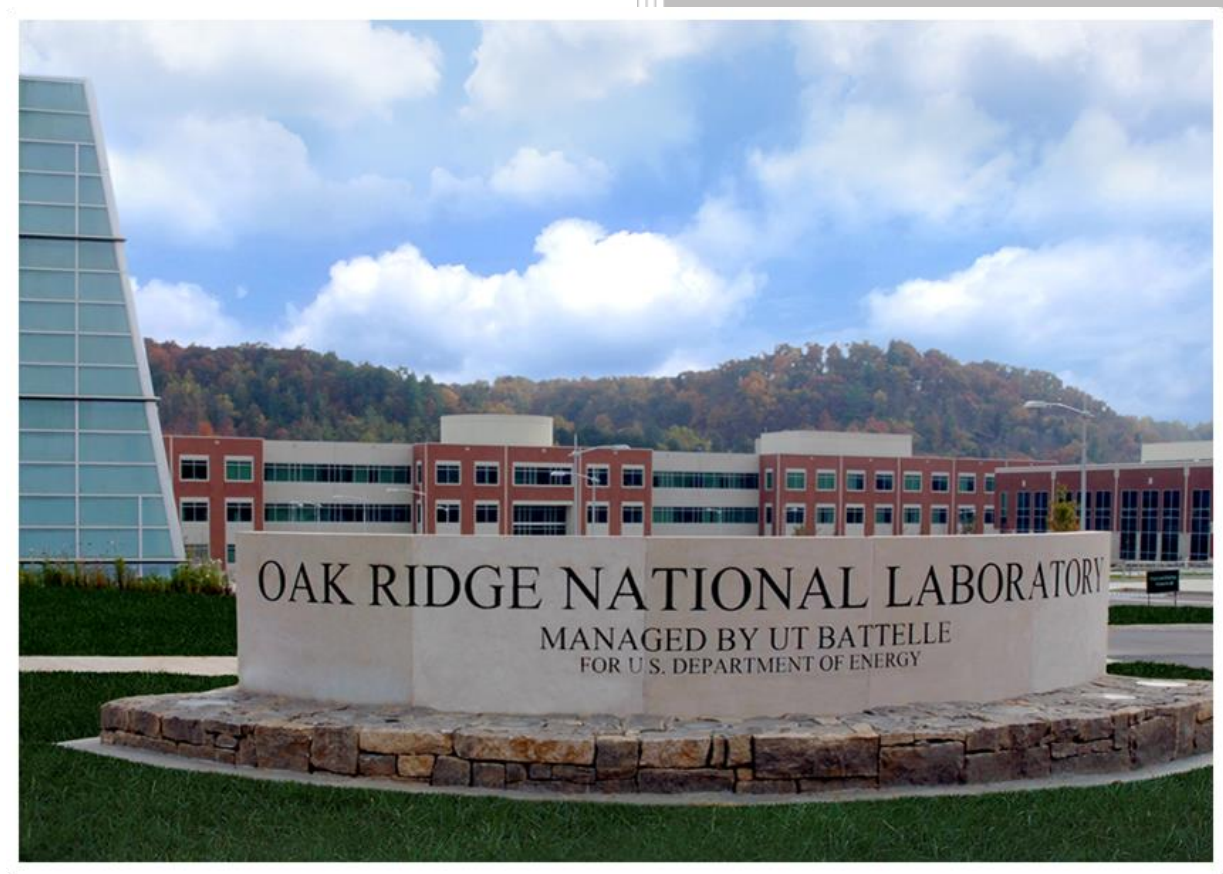

Roderick Jackson

Omer C. Onar Harold Kirkham Emily Fisher Klaehn Burkes Michael Starke Olama Mohammed George Weeks

April 2015 


\title{
DOCUMENT AVAILABILITY
}

Reports produced after January 1, 1996, are generally available free via U.S. Department of Energy (DOE) SciTech Connect.

Website http://www.osti.gov/scitech/

Reports produced before January 1, 1996, may be purchased by members of the public from the following source:

\author{
National Technical Information Service \\ 5285 Port Royal Road \\ Springfield, VA 22161 \\ Telephone 703-605-6000 (1-800-553-6847) \\ TDD 703-487-4639 \\ Fax 703-605-6900 \\ E-mail info@ntis.gov \\ Website http://www.ntis.gov/help/ordermethods.aspx
}

Reports are available to DOE employees, DOE contractors, Energy Technology Data Exchange representatives, and International Nuclear Information System representatives from the following source:

Office of Scientific and Technical Information

PO Box 62

Oak Ridge, TN 37831

Telephone 865-576-8401

Fax 865-576-5728

E-mail reports@osti.gov

Website http://www.osti.gov/contact.html

This report was prepared as an account of work sponsored by an agency of the United States Government. Neither the United States Government nor any agency thereof, nor any of their employees, makes any warranty, express or implied, or assumes any legal liability or responsibility for the accuracy, completeness, or usefulness of any information, apparatus, product, or process disclosed, or represents that its use would not infringe privately owned rights. Reference herein to any specific commercial product, process, or service by trade name, trademark, manufacturer, or otherwise, does not necessarily constitute or imply its endorsement, recommendation, or favoring by the United States Government or any agency thereof. The views and opinions of authors expressed herein do not necessarily state or reflect those of the United States Government or any agency thereof. 
Energy and Transportation Sciences Division

\section{OPPORTUNITIES FOR ENERGY EFFICIENCY IMPROVEMENTS IN THE U.S. ELECTRICITY TRANSMISSION AND DISTRIBUTION SYSTEM}

Roderick Jackson, Oak Ridge National Laboratory

Omer C. Onar, Oak Ridge National Laboratory

Harold Kirkham, Pacific Northwest National Laboratory

Emily Fisher, Lawrence Berkeley National Laboratory

Klaehn Burkes, Savannah River National Laboratory

Michael Starke, Oak Ridge National Laboratory

Olama Mohammed, Oak Ridge National Laboratory

George Weeks, Savannah River National Laboratory

April 2015

Prepared by

OAK RIDGE NATIONAL LABORATORY

Oak Ridge, TN 37831-6283

managed by

UT-BATTELLE, LLC

for the

U.S. DEPARTMENT OF ENERGY

under contract DE-AC05-00OR22725 



\section{CONTENTS}

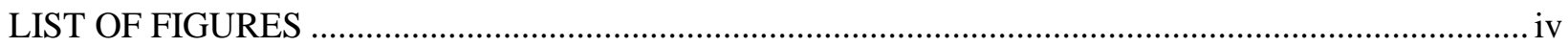

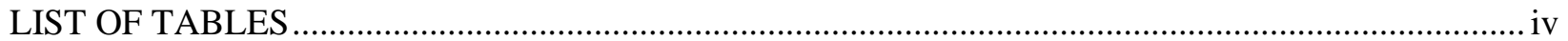

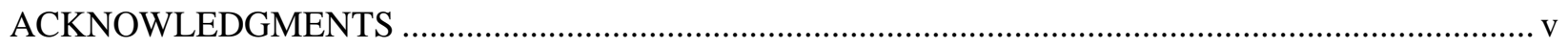

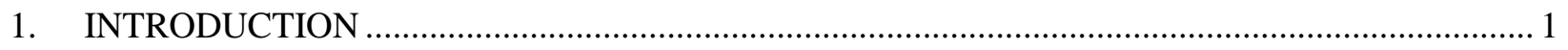

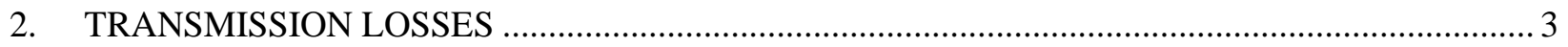

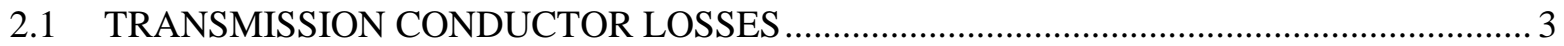

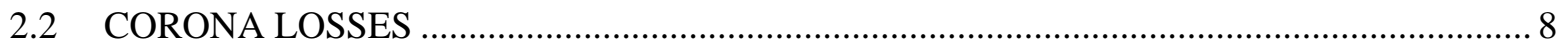

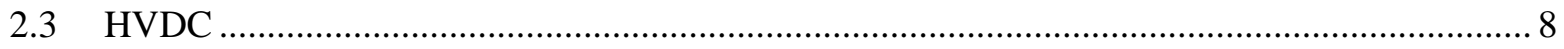

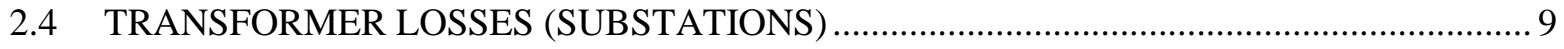

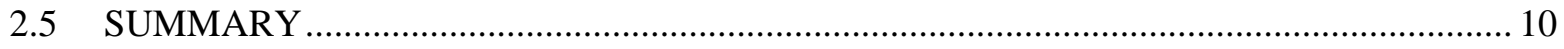

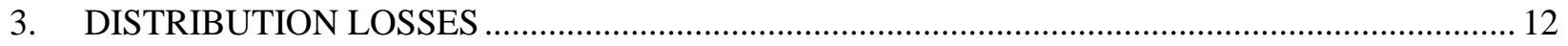

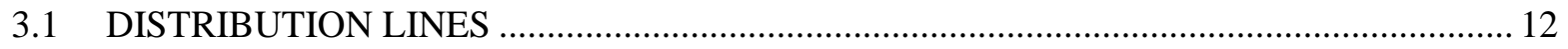

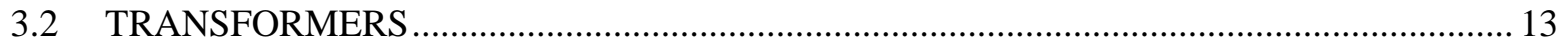

3.3 OTHER OPPORTUNITIES TO REDUCE DISTRIBUTION SYSTEM LOSSES ................ 14

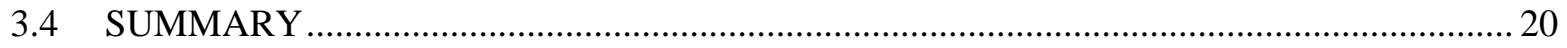

4. TECHNOLOGY CHARACTERIZATION and OPERATIONAL STRATEGIES ......................... 21

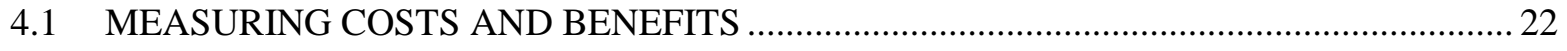

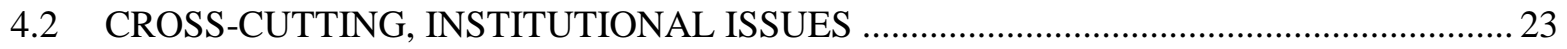

5. SYNTHESIS: WHAT EFFICIENCY IMPROVEMENTS ARE POSSIBLE .................................25

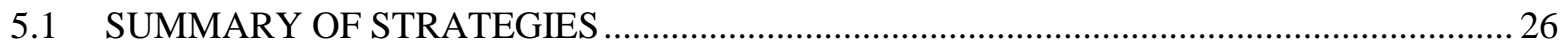

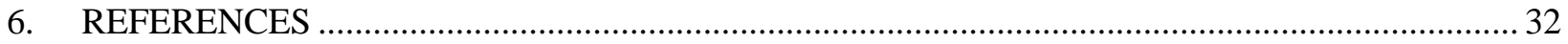

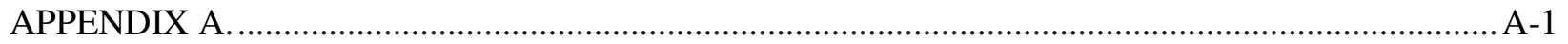




\section{LIST OF FIGURES}

Figure 1. U.S. and World electric power transmission and distribution losses as a percentage of total output. Source: Ref. [1]

Figure 2. Kelvin's Law as presented by A.S. Pabla. Source: Ref. [2] ............................................... 2

Figure 3. Losses as a function of power transmitted for several voltage classes..................................... 6

Source: Adapted from Evan Wilcox, "765 kV Transmission Facts," presented to Southwest

Power Pool Cost Allocation Working Group, May 28, 2008

(www.spp.org/publications/00\%20-\%20CAWG\%20Agenda\&Bkgd\%2020080528.zip).

Figure 4. Percent of total possible losses of a typical $1500 \mathrm{kVA}$ distribution transformer. Source:

Ref. [46].

Figure 5. Street Scene, August 2014, Pacific Northwest. (Photo by H. Kirkham, PNNL)

Figure 6. Phase-balance electronics. Source: Adapted from T. S. Win, E. Hiraki, M. Okamoto, S.

R. Lee, and T. Tanaka, "Constant DC capacitor voltage control based strategy for active

load balancer in three-phase four-wire distribution system," pp. 1560-1565 in

Proceedings of 2013 International Conference on Electrical Machines and Systems, IEEE, 2013.

Figure 7. Typical Low Power Factor Industries Source: Ref. [59].

\section{LIST OF TABLES}

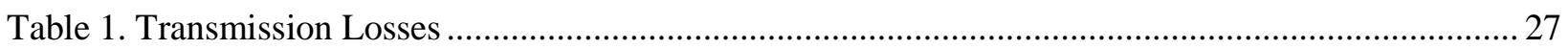

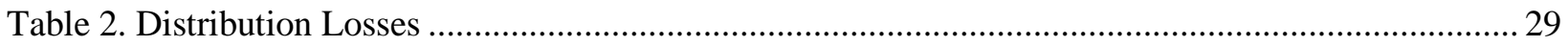

Table A-1: Indicative potential electricity transmission loss reductions in Australia............................. A-1

Table A-2: Indicative potential loss reductions in electricity distribution networks in Australia...............-2 


\section{ACKNOWLEDGMENTS}

This document was sponsored by the Department of Energy's Office of Energy Policy and Systems Analysis. We wish to acknowledge John Agan who was an important contributor to the document's scope and content. Similarly, we thank Carla Frisch who contributed to its design and execution.

We also wish to thank the following reviewers for their comments and feedback.

Nick Abi-Samra, DNV GL

Gil Bindewald, DOE

Marilyn Brown, GA Tech

Alberto Del Rosso, EPRI

Stan Hadley, ORNL

Tim Heidel, DOE

Carl Pechman, DOE

Larry Mansueti, DOE

Burak Ozpineci, ORNL

Cyndy Wilson, DOE 



\section{Opportunities for Efficiency Improvements in the U.S. Electricity Transmission and Distribution System}

\section{INTRODUCTION}

Since 2000, more than 172 quads of electricity have been transmitted on the U.S. transmission and distribution (T\&D) grid. Given this significant amount of energy flow, establishing and maintaining an efficient T\&D grid is paramount. As shown in Figure 1 below, the total percentage of overall losses in the U.S. electric grid is approximately $6 \%, 30 \%$ lower than the world average since 2000 . While these efficiency losses appear to be relatively small from a percentage perspective, the total estimated electricity loss during this time is 10.8 quads.

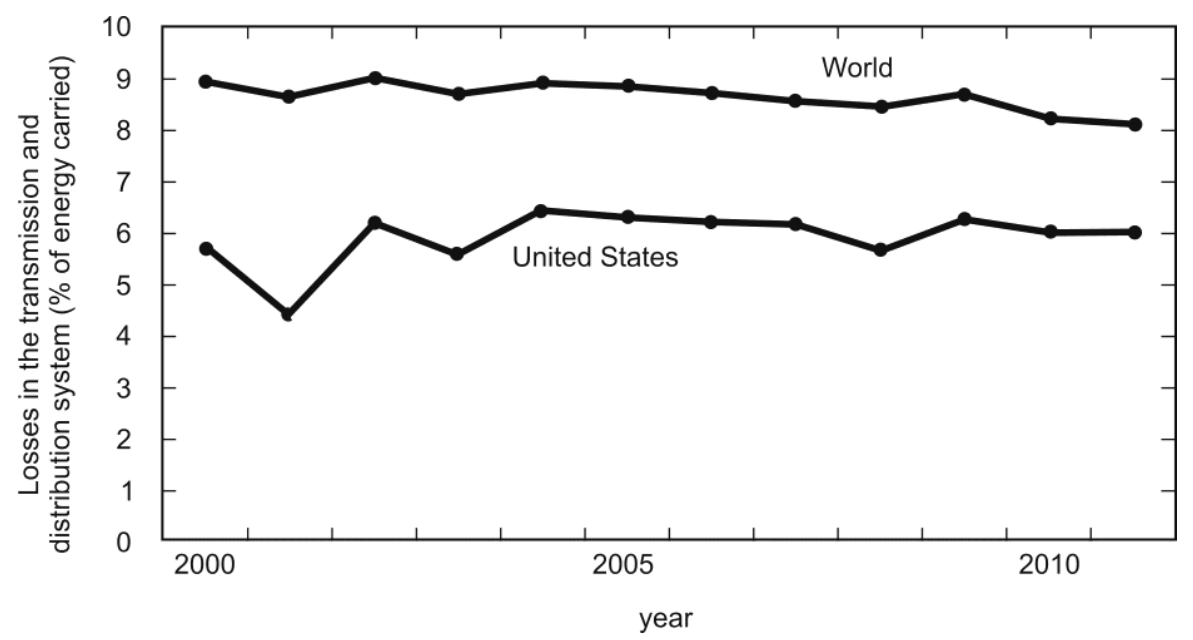

Figure 1. U.S. and World electric power transmission and distribution losses as a percentage of total output. Source: Ref. [1]

A study of one state, New York, found that transmission losses ranged from 1.5 to $5.8 \%$ for the utilities involved, and distribution losses ranged from 1.9 to $4.6 \%$. The New York utilities had already undertaken common strategies for reducing transmission and system distribution losses including distribution capacitor installation, conservation voltage reduction, phase balancing, upgrading voltage class, and installing more efficient transformers. This study did not estimate potential for further loss reduction.

Since the beginning of the power industry, a law developed by Lord Kelvin (1824-1907) has been used to guide system design that considers both cost and energy losses. One expression of the law is this:

The most economical cross-section area for an electric conductor is that for which the cost of energy lost in a given period equals the depreciation and the interest on the capital for the same period. [2] 
Students in power classes sometimes see a graph such as the one in Figure 2:

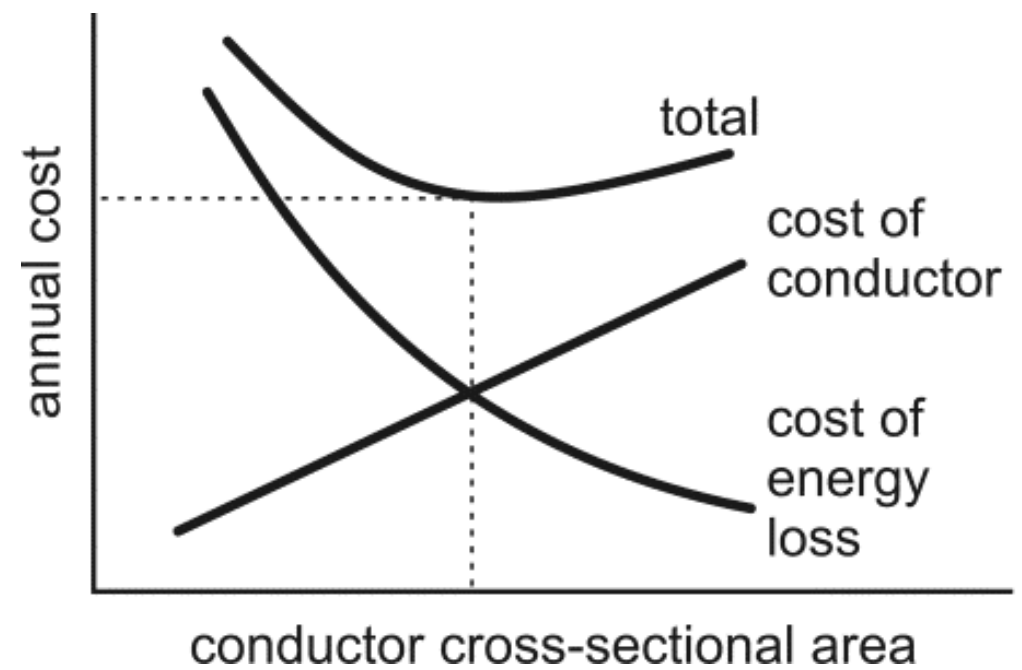

Figure 2. Kelvin's Law as presented by A.S. Pabla. Source: Ref. [2]

The graph shows that as the planned conductor cross section increases, the losses decrease but the cost increases. The point at which the costs are the same corresponds to the minimum total cost.

In this document, we examine various loss mechanisms in the power system, and summarize research into the potential for loss reduction from each between now and 2030. Surveyed research focuses on costeffective efficiency improvements, where measured benefits outweigh costs, rather than on all technically feasible improvements, which are unlikely to be of interest to grid operators, policymakers or consumers.

The remainder of this document is organized as follows: Section 2 describes the categories of efficiency loss in the transmission system, which primarily consist of ohmic and corona losses; Section 2 also describes technologies to deal with these loss categories. Section 3 describes loss categories and potential technology solutions for them in the distribution system. The efficiency losses in distribution primarily come from transformers and system-level inefficiencies, and multiple technology solutions exist for each (including alternative system designs). Section 4 classifies strategies for reducing system losses and highlights important policy considerations, such as the case-sensitivity of cost-benefit analyses and the cross-cutting institutions that govern the transmission and distribution system. Section 5 provides a synthesis of the knowledge presented in other sections and provides an example of the kind of study that could be conducted to identify strong opportunities for improving the efficiency of transmission and distribution systems in the United States. 


\section{TRANSMISSION LOSSES}

Electrical energy is transmitted by engineered systems that have their origins in methods and businesses developed a hundred years ago. Transmission systems are the highest-voltage part of the power delivery grid. They are operated as interconnected networks, using a small number of standardized voltages. The highest voltage in use in the United States is $765 \mathrm{kV},{ }^{1}$ connected within a system to the next lowest voltage, $345 \mathrm{kV}$. Other regions in the United States use $500 \mathrm{kV}$ as the highest voltage and $230 \mathrm{kV}$ as the next lowest [3], [4].

Technological advances (such as increasing the voltage level) have significantly improved the efficiency of the system, so that only about 5.1\% of the total energy delivered in 2012 in the United States was lost during transmission and distribution [5]. While the total percentage loss is relatively low, this results in approximately 0.7 quads of energy lost per year. The causes of these losses are many, and there is no single panacea to improve efficiency. There are often many interacting phenomena. Reducing the losses observed on a particular line segment or component may cause increased losses or costs elsewhere. Furthermore, physical limits as well as market and policy constraints must be taken into account.

This section provides a view of the electrical losses associated with physical systems in any of these transmission schemes. These losses can primarily be found in conductors and other transmission equipment. In Section 5 of this document, Tables 1 and 2 summarize the various types of loss and loss reduction strategies.

\subsection{TRANSMISSION CONDUCTOR LOSSES}

Conductor losses can come in the form of ohmic losses, skin effect losses, and proximity effect losses. We assess each in turn.

Ohmic loss refers to the Joule heating loss in the resistance of transmission line conductors. This heating is a function of the resistance of the conductor and the line current $\left(I^{2} R\right)$. Conductor properties such as material, configuration, size, temperature, and length all have impact on this resistance [3]. Several approaches, reconductoring and the use of superconductors, are available to improve these losses:

(a) Reconductoring: Reconductoring a transmission line implies replacing the existing conductors with newer conductor designs consisting of better properties or design features. For those transmission lines whose transfer capacities are limited by their thermal ratings, reconductoring can be a feasible solution to improve the thermal performance and reduce line loss. Several types of advanced conductors or technologies can be considered. Conductors of larger diameter have smaller per unit resistance than those of the same material but smaller diameter. Therefore, reconductoring a line with larger-diameter conductors can reduce the loss. A larger conductor of the same type as the old one is a common candidate for this application. However, there are constraints on the diameter increase of the new conductors. Fitting hardware has to be replaced due to the diameter change. Mechanical structures (insulator strings and towers) may need to be redesigned: a bigger conductor will have more wind loading, and that is commonly the limiting factor in the tower design. The cost of the restructuring will exceed the benefit of loss reduction if the new conductor is too large. However, a diameter increase within $10 \%$ can sometimes be tolerated without significant structure modification [6], [7].

\footnotetext{
${ }^{1}$ System voltages are expressed as the phase-to-phase value.
} 
Unlike standard round-wire conductors, trapezoidal-wire conductors use aluminum strands of a trapezoidal cross-section to form the layers around a steel core. The trapezoidal wires improve the compactness of the strands and allow the conductor to incorporate more aluminum with the outside diameter unchanged. Trapezoidal wires conductors with the same diameter as the round-wire conductors are claimed by the manufacturers to achieve $20 \%$ to $25 \%$ increase of metal area, i.e., $15 \%$ to $20 \%$ decrease of per-unit-length resistance [7], [8], [9]. A decrease of $17 \%$ in resistance per unit length would decrease losses to about $70 \%$ of the original.

(b) Superconductors: Superconductor is a form of specially designed and made conductor that has extremely low (ideally zero) electrical resistance when material is cooled below a characteristic critical temperature. Superconducting cables can deliver 3 to 5 times more power than a conventional cable of the same size and voltage rating [10]. A superconducting cable becomes worthy of consideration if the transmission system is underground. It must be cautioned that superconducting cables are not considered for efficiency or cost reasons. Conventional copper cable costs about $\$ 25$ per kA per meter. In contrast, superconducting cable was reported recently as $\$ 200$ per kA per meter [11]. It is the increase in power capability that matters: it translates in more power over a given rightof-way, and in densely populated urban areas retrofitting cables into existing ductwork offers great potential. Where right of way is hard to find, the increase in capability is far more important than the losses.

(c) Controlling power flow: Power flow control is an electrical device or system that can provide fastacting active or reactive power on transmission lines. In some cases, a power flow controller regulates the voltage at the point of connection or changes the line impedance in order to control the power flow. Sometimes, alternate or additional set of conductors are used to control the load/power flow on the main line. Although using an alternative set of conductors to control power flow is simple, it is rarely done due to equipment costs. Without this capability, the flow of power in a network is in some ways akin to the flow of water in a network of pipes: it adjusts itself to the circumstances, in this case the impedance of the lines and the details of the voltages at the various points of interconnection of the network (known as buses). The direction that the current flows in the network does not guarantee minimum losses in delivering power. Nor is loss-minimization an optimization done by the system operators. Operators make adjustments to the power system by changing generation settings and setting voltages, but their objective is to maintain a balance between load and generation while allowing for the fact that faults sometimes occur, and generation and transmission capability must have some reserve. In this, they are often guided by the results of software called Optimal Power Flow [12].

The use of Flexible AC transmission (FACTS) and unified power flow controllers (UPFC) are one of the few methods for advanced control of power flow [13], [14], [15]. In most of these developments, devices are shunt connected ${ }^{2}$ and power electronics do not handle the entire transmission system power. Instead, they absorb or inject a much smaller portion of it. A recent ORNL project proposes a magnetic amplifier based saturable reactor core for power flow control that uses power electronics in auxiliary circuit with only the reactor in series with the transmission line. These are power electronic systems that modify the relationship between voltage and current at key locations, effectively modifying line impedance. They are not widely utilized. There are five major reasons for this [16]:

\footnotetext{
${ }^{2}$ Power flow control or FACTS devices can be connected to the transmission lines either in series (in-line) or in shunt (parallel). When these devices are connected in series, their power rating should be at least equal to the power rating of the transmission line since all of the transmission line power has to go through the series connected device. In shunt connection, only a relatively smaller portion of the transmission system power is absorbed or provided by the shunt connected system; therefore, its power rating can be smaller than that of the transmission system.
} 
(1) often custom silicon devices are needed, and the engineering effort raises the first cost; (2) fault levels and insulation needs can overstress the power electronics; (3) the systems have not demonstrated the reliability levels needed for wider acceptance; (4) the skills needed to operate and maintain the systems are not within the core competency of many utilities; and (5) the total cost of ownership is not seen as acceptable. Research continues to address these issues.

In order to address the drawbacks of the conventional FACTS systems, the Advanced Research Projects Agency - Energy (ARPA-E) has funded several projects through its Green Electricity Network Integration (GENI) program. ${ }^{3}$ In most of these projects, the idea is to have a passive device connected to the transmission line which can be controlled with relatively smaller power electronics systems. In most of these developments, line losses can be reduced; however, the impact has not yet been quantified.

Optimal network reconfiguration refers controlling the power flow across multiple systems feeding a region over the meshed network. For a given instance and set of conditions, there is an optimal configuration that meets the power demand in most effective, efficient, and flexible way. In addition, optimal network reconfiguration has been shown to provide potential loss reductions [17], [18]. This research is currently being investigated with an ARPA-E grant [19].

(d) Decreasing reactive power flow: If the current and the voltage are not in phase in some particular line, the total current is greater than that required to furnish just the power of the load. The circuit is said to be carrying "reactive" power (in addition to the real power, which is what does the work at the load), which can be considered a "phantom" power that moves between parts of the power system that are either inductive or capacitive. Many motors and transformers have this characteristic, as do power lines themselves. If the value of the current and the voltage in an AC system are multiplied, the result is called the "apparent power." It will be greater than the real power unless the reactive power is exactly zero. The ratio of the real power to the apparent power is called the "power factor." It is a number equal to or less than one.

Reactive power can be compensated if the current in the circuit leads the voltage, the load is slightly capacitive; if the current lags the voltage, the load is inductive. In both cases, a shunt capacitor can be used to compensate. The compensation has the effect of reducing the current, and therefore reducing the losses in delivery of the power. Almost all utilities penalize their large customers for reactive power, or otherwise incentivize them to correct their own reactive power consumption. ${ }^{4}$

The use of shunt compensation in this way is common in the distribution system, where the motive is not so much to reduce losses as it is to manage voltage. In both the transmission system and the distribution system, a lightly-loaded system with relatively low current tends to "look" capacitive to the power system which causes the voltage to increase. When the load is heavier, the voltage on the line tends to decrease. In distribution, where voltage control is important to the customer, capacitors are often added to increase the voltage. They are switched in (usually by time-clock control or through instantaneous measurements of active/reactive power and the power factor) for voltage management purposes. In transmission systems, it is more often the case that lines that are lightly loaded (for instance at night) will be compensated by shunt reactors.

\footnotetext{
${ }^{3}$ The details of the program can be found at http://www.arpa-e.energy.gov/?q=arpa-e-programs/geni.

${ }^{4}$ Some examples of utility companies charging for reactive power include but not limited to Duke Energy (http://www.duke-energy.com/pdfs/understand-bill-guide-in.pdf) and Pacific Gas \& Electric (http://www.pge.com/includes/docs/pdfs/mybusiness/customerservice/energystatus/powerquality/power\%20factor-revised-8-9-07.pdf)
} 
(e) Increasing voltage: Increasing voltage on the AC system will result in a decrease in the current for a given power, and hence lower losses. There are two possibilities: the voltage on an existing line could be increased slightly above its "nominal" value, or an "overlay" at higher voltage could be built. The decrease in losses with voltage class is illustrated in Figure 3, which shows the losses in MW associated with transmitting various levels of power over a distance of 100 miles.

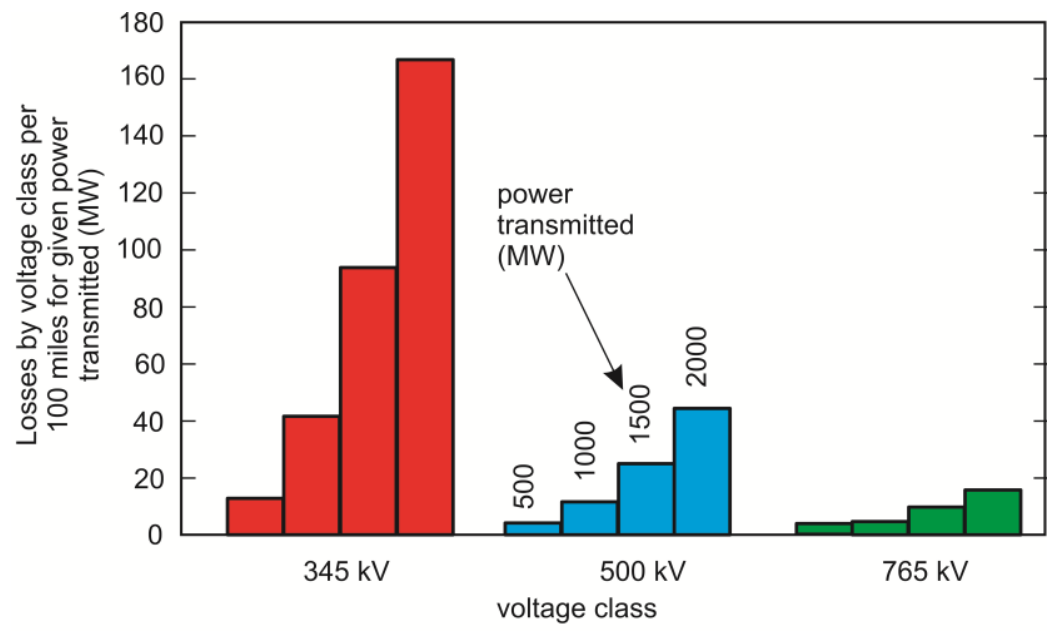

Figure 3. Losses as a function of power transmitted for several voltage classes.

Source: Adapted from Evan Wilcox, "765 kV Transmission Facts," presented to Southwest Power Pool Cost

Allocation Working Group, May 28, 2008 (www.spp.org/publications/00\%20\%20CAWG\%20Agenda\&Bkgd\%2020080528.zip).

While adding an overlay at higher voltage is something that is routinely considered by system planners, it represents a major system enhancement that requires consideration of multiple factors, in addition to the effect on losses. Adding an overlay at a higher voltage is a possibility for systems whose highest level is $345 \mathrm{kV}$ or $230 \mathrm{kV}$. However, the cost and complexity of a new line are matters of system planning in which losses in existing lines play only a small part.

In the absence of new investment in an overlay, from an operational standpoint, just increasing the voltage slightly is a feasible option on some systems. Some $500-\mathrm{kV}$ systems are operated as high as $550 \mathrm{kV}$ [20]. For example, for the same amount of load power at the end of the transmission line, if the operating voltage of the line is increased by $10 \%$, the line losses reduce by $17.3 \%$. As a different test case, increasing the line voltage by $15 \%$ reduces the losses by $24.3 \%$ for the same amount of load power. However, there are cost impacts to consider if the voltage is increased by moving to a higher voltage class, such as from $500 \mathrm{kV}$ to $765 \mathrm{kV}$. The cost of system components (transformers, switches, and circuit breakers) increases significantly with the higher voltage class. Physical limits are also present. Work at a number of laboratories in the 1960s and 1970s explored voltages above 765 $\mathrm{kV}$ and elucidated the effects of conductor surface condition and the effect of weather [21], [22], [23], [24]. The research for above $765 \mathrm{kV}$ transmission found that the bundle had to be so large due to the electric fields that the economics of line construction no longer favored higher voltages. Hence, for all 
practical purposes, there are no AC power lines in operation above the level reached in the $1960 \mathrm{~s}^{5}$ although recently China installed ultra-high voltage systems that operates at $1000 \mathrm{kV}$ AC and \pm 800 $\mathrm{kV}$ for DC transmission. China's decision to install ultra-high voltage transmission is due to the fact that most power plants are far away from high energy consuming areas where they have manufacturing plants, other commercial buildings, and highly populated cities.

(f) Shield wire segmentation: Shield wires are generally steel cables with relatively higher resistance (with respect to phase conductors) and losses in these are due to the mutual coupling from the phase conductors. Such losses would increase with the loading of the transmission line. Induced currents in the shield wires can circulate through the towers and tower footing resistance, and of course ground. Therefore losses can be reduced by "breaking" or segmenting the shield wires or by reducing the mutual coupling with the phase conductors. As transmission system efficiency becomes more of a priority, some transmission operators may consider applying segmented shield wires to lower voltage lines, such as $115-\mathrm{kV}$ and $230-\mathrm{kV}$ lines. In addition, insulating the shield wire from the tower would eliminate the path, and thus the losses to ground.

(g) The skin effect: The skin effect is the increase in resistance caused by current concentrating at the surface of the conductor due to a non-uniform magnetic flux linkage across a conductor [25], [26]. At Radio Frequency, using wires with multiple individually insulated strands (called Litz wire) reduces the effect. However, at power frequencies, the effect is generally unimportant, and in fact is smaller in magnitude than the effect of normal temperature fluctuations. ${ }^{6}$ The current is indeed moved toward the outer edge of the wire. With an aluminum material, most of the current is carried in a layer just over $1 \mathrm{~cm}$ thick, a distance known as the skin depth. Very few power lines have an aluminum thickness greater than this skin depth anyway, so except for a small number of very large high-current applications (above $2000 \mathrm{~A}$ or so), skin effect can be ignored. High voltage lines are usually built as bundles of smaller sub-conductors in order to reduce corona effects (see below) which also in part reduces the skin effect losses.

(h) The proximity effect: The proximity is a variation on skin effect in which the magnetic field from one conductor is moving charge-carriers in another [27], [28]. If the distance between conductors is more than a few $\mathrm{mm}$, the effect is negligible. The distance between conductors is usually more than that.

An alternative to targeting the resistance is to reduce the current. A key driver of this improvement is the realization that losses are a function of the current squared. Hence, cutting the current by a factor of two reduces the conductor loss by a factor of four. Rerouting power flow, decreasing reactive power, and increasing the voltage are three mechanisms for reducing the conductor losses.

\footnotetext{
${ }^{5}$ Lines operated with direct current behave differently in several respects as far as field and corona effects are concerned. The surface field can be higher than with ac without incurring a power loss or noise penalty, but the design of insulation systems becomes very much more difficult. DC lines are operated at up to $800 \mathrm{kV}$ at the time of writing.

${ }^{6}$ Since not all the conductor is being used, the resistance is increased. For example, a conductor known as Curlew has a DC resistance of $0.0909 \mathrm{ohms}$ per mile at $25^{\circ} \mathrm{C}$, and a $60-\mathrm{Hz}$ resistance of $0.0924 \mathrm{ohms}$ per mile, an increase of less than $7 \%$. However, the same conductor at $75^{\circ} \mathrm{C}$ has a resistance of 0.1101 , an increase over the $25^{\circ} \mathrm{C}$ value of $19 \%$, and at $100^{\circ} \mathrm{C}$ it is 0.1190 , the resistance is nearly $29 \%$ higher than its value at $25^{\circ} \mathrm{C}$. At this temperature the losses would be increased by $66 \%$ over the $25^{\circ} \mathrm{C}$ value. The effect of temperature is clearly much more important that the skin effect. An example of Curlew wire specifications can be found at http://www.southwire.com/ProductCatalog/XTEInterfaceServlet?contentKey=prodcatsheet16
} 


\subsection{CORONA LOSSES}

The losses discussed so far have been related to the current in the system. Corona loss is an effect of the voltage on the system. In some cases, small short-lived arcs, usually about as long as the diameter of the conductor, can be seen on high voltage lines. The arcs are caused by the local breakdown of the air. This phenomenon, known as corona, is a result of distortions in the intensity of the electric field, usually created by raindrops and accompanied by an audible noise, electromagnetic noise, and a power loss.

Corona was extensively studied in the 1960s and 1970s as the need for higher-voltage power lines became apparent. Much of the work was aimed at producing a line design with acceptable noise performance. It was found that the power loss is correlated with the 120-Hz component of the audible noise [24] with the result that when the noise level is acceptable, the power loss is also considered acceptable. Corona is weather dependent, and because of changes in the nature of the surface of the conductor over time, it depends on the age of the conductor. (Older wires usually perform better in terms of Corona losses. A new conductor is smooth, and covered with grease from the manufacturing process. As a result water beads on the surface, and causes field intensification that produces the collective "corona effects." When the conductor is aged, its surface becomes rough and dirty, and it becomes hydrophilic. The raindrops wick into the interstices between the strands, and all the corona effects are reduced except in very heavy rain.) The recent advances in material science allowed for the use of superhydrophobic materials which could also be used to reduce the Corona losses. A comparison of line losses is difficult because the corona power loss is independent of the current, whereas the resistance loss $\left(I^{2} R\right)$ is dependent on loading. The average annual corona loss is about ten times smaller than the resistance losses [24]. Illustrative numbers are provided for a hypothetical 500-kV line in Albany, NY: maximum loss $108 \mathrm{~kW}$ per mile, average loss (over a year) $5.7 \mathrm{~kW}$ per mile.

Corona loss is of importance only on high voltage lines of $345 \mathrm{kV}$ and higher, because it is an effect caused by geometric enhancement of the electric field at the conductor surface, and the starting field is lower on lines of lower voltage class. Once a power line has been built, the only way to reduce the corona loss would be to reduce the voltage. While that is generally counter-productive in terms of system operation, there may be some situations in which a line is being rained on, is not heavily loaded and could be operated at a slightly reduced voltage. The corona loss changes as a power of the voltage, so for example a loss reduction of $25 \%$ may be achieved with a voltage reduction of perhaps $5 \%$ [24]. The 5\% reduction in operating voltage increases the ohmic line losses by $10 \%$. Therefore, reducing corona losses by decreasing the voltage could be implemented during periods of low line loading, if the benefits can justify the effort [29]. The overall impact on efficiency would be climate-dependent.

\section{$2.3 \quad$ HVDC}

So far in this section, we have considered power transmitted by alternating current (AC). High voltage DC (HVDC) has been in use in some locations, and may play a bigger role in the future. HVDC has three roles in power delivery. ${ }^{7}$ It can connect systems that are not synchronous (such as Texas and New

\footnotetext{
7 There is what might be considered a fourth role for DC, and that is that the power flow is controllable. Indeed it must be controlled. In some circumstances this controllability can be used to increase the stability of the AC power system [30]. That role is rarely invoked, however, as it cannot be known when such a system is designed whether action by the DC line is always the correct action for a disturbance somewhere on the power system). While the converter costs add to the capital costs, the lower civil engineering associated with a line of two conductors instead of three balances these costs at a distance known as the "breakeven distance." For longer distances, DC is cheaper to build. [Deepak Tiku, "DC power transmission," IEEE Power and Energy Magazine, 12(7), 76-96, March/April 2014.]
} 
Mexico), it can deliver power that has to be in a cable without running into a distance limit, and it can deliver bulk power large distances for lower capital cost than an all-AC system.

A DC scheme works by converting AC to DC - often at very high voltage. The power is then transmitted as DC on a line or a cable, and converted back to AC at the receiving end. The line losses depend only on the resistance of the line and the current flowing in it; the losses do not depend on the voltage on the line or the power factor of the load. This loss could be reduced only by the costly measure of reconductoring. As an example, consider the Sylmar-Celilo line located at the Pacific DC Intertie that transmits electrical energy from Pacific Northwest to Los Angeles. It delivers about $3 \mathrm{GW}$ at $\pm 500 \mathrm{kV}$ in a distance of about $1300 \mathrm{~km}$ (850 miles), with a loss of about $11 \%,{ }^{8}$ not including the converter losses.

Converter losses consist of current dependent conduction losses and voltage and current dependent switching losses. The converter losses can only be reduced by reducing the voltages and currents or by using different switches and diodes or converter topologies. A recent converter technology using insulated gate bipolar transistors in a multi-level modular topology has led to a reduction of converter losses to about $1 \%$ of the transmitted power in the newest converters, compared to 2 or $3 \%$ in a typical pulsewidth-modulated (PWM) converter and almost on a par with the earlier thyristor technology [31], [32], [33].

With the recent advances in wide bandgap (WBG) power semiconductor device technologies; these associated losses can be further reduced. These wide bandgap devices are extremely efficient, they can handle high temperature operation (reduced cost and complexity of cooling systems), and they can switch at higher frequencies resulting in reduced size and cost of passive components (capacitors and inductors used in power electronic converters and filters). Since WBG devices have higher breakdown voltages, a smaller number of devices can be set in series compared to Si devices to achieve higher voltage operation [34]. However, these devices still have higher costs and lower current ratings and are not yet ready for high voltage, high current applications. On the other hand, these devices are increasingly being adopted in lower voltage applications and high voltage power system applications are likely to follow over time.

In these HVDC applications, almost all the systems so far built have been point-to-point, without networking. Future direct current systems might be used to play a different role in power delivery [30]. It is possible to take advantage of the controllability of the converters to add stability and (in the case of some converters based on what is called "voltage-source" technology) voltage support to the underlying $\mathrm{AC}$ power system. In addition, line currents can be reduced by shifting the distribution of power flow in transmission systems where excess capacity exists.

\subsection{TRANSFORMER LOSSES (SUBSTATIONS)}

Transformers are located throughout the power system, in both transmission and distribution. In terms of numbers, the distribution system is home to far more transformers than the transmission system, but they are smaller. Roughly speaking, in any interconnection, the power in the transmission system is equal to the sum of the power in the distribution system, and so the ratings of the transformers in each must add up to about the same number. The locations where the larger transformers are located are generally known as substations, ${ }^{9}$ though not all substations contain transformers. A substation without transformers may be a switching station, where the network configuration can be changed, but power is not stepped up or down

\footnotetext{
${ }^{8}$ The resistance of the conductor is, of course, temperature dependent. It can be as low as about 16 ohms and as high as about $22 \mathrm{ohms}$. The loss figure given here is for a value of $19 \mathrm{ohms}$.

${ }^{9}$ The locations where load is served via a pole-top transformer are not known as substations. They are simply transformers.
} 
in voltage. Substations called primary stations or sometimes bulk-infeed stations or bulk supply points connect the distribution system to the transmission network. At these locations, there are typically a number of circuits bringing power into the station at high voltage, and a number of transformers stepping the voltage down.

In this document, the question of transformer losses is mainly dealt with in the section on distribution, and all of the discussion there applies to transmission-level transformers as well. Transmission-class transformers have a few attributes that they do not share with distribution transformers, and we will mention some here.

Big transformers are expensive, and take a long time to acquire. It may take more than a year to obtain a replacement transformer should one fail. So while a spare transformer may be available on a power system, mission assurance dictates that everything possible be done to avoid failure. Typically, that means keeping the transformer cool. The heat caused by the losses in the transformer is removed by a cooling system not unlike the one that cools the internal combustion engine on a car. These measures are needed because, for any given shape, the volume (and hence the amount of heat) increases as the third power of the linear dimension, whereas the surface area increases as the square of the linear dimension. Doubling the size of a transformer therefore increases the amount of heat to be removed by a factor of eight, but it only increases the surface area by a factor of four. ${ }^{10}$ A heat exchange fluid is pumped through the transformer (oil is typically used because it has excellent electrical insulation properties) and forced air is used to extract the heat and couple it to the atmosphere.

This cooling system, with oil pumps and air fans, is itself a consumer of electricity, and could be considered as a "transformer self-consumption." To minimize the consumption, the cooling systems are usually controlled by thermostats, as in cars. Without the forced cooling, the transformer rating would have to be decreased, perhaps to only $60 \%$ of its full rating. According to an ABB datasheet (ABB Megawatt Station, 1.25MW PVS800-MWS), in operation, the self-consumption power of a $1.25 \mathrm{MW}$ transformer is less than $1200 \mathrm{~W}$. This corresponds to about $\sim 0.09 \%$ of the rated power of the transformer. This ratio will also be true for transformers with higher power ratings since losses and the heat generation is relative to the transformer rating and the cooling requirement increases proportionally.

It should also be remembered that reliability rules may mandate that a substation be able to carry its rated power with one transformer out of service. That is often taken into account that the remaining transformers can be overloaded (sometimes to twice their nominal rating) for a short time. Because of the care with which the transformers are selected (factors such as their impedance and their capacity to regulate voltage are also important), it is unlikely that there are any considerations that would lead to a worthwhile reduction in the power consumption of these auxiliary systems. Loss reduction opportunities in transformers are discussed further in the Distribution section of this document.

\subsection{SUMMARY}

While there are numerous technology options for remedying efficiency losses in transmission systems, the economic and performance tradeoffs presented by these technologies remain important. Reconductoring and superconductors offer means of overcoming ohmic losses through expanding the size or altering the structure of the transmission system's conductive elements. However, reconductoring presents costs of materials upgrades/replacements and possible system redesign due to over-expansion of conductor

\footnotetext{
${ }^{10}$ Readers who are interested in biology will recall that it is more difficult to extract the heat from the core of a large animal such as an elephant than it is the core of a small animal such as a mouse. The large ears on the elephant are a mechanism that serves both to increase the surface area and to move the air.
} 
diameter. Superconductors also present eightfold cost increases over their conventional copper counterparts and are only available for underground transmission systems. Power flow control and optimization technologies such as FACTS can reduce ohmic losses by reducing current and increasing voltage, but these technologies can be expensive and may require system redesign if moving from a $500 \mathrm{kV}$ system to a $750 \mathrm{kV}$ system. However, if designed properly, FACT systems are very effective and payback period can be reduced. Corona losses are on average smaller in magnitude than ohmic losses and may only be reduced through reducing voltage, which is only an option in special operating circumstances. HVDC lines serve valuable purposes in the existing grid but may not necessarily be more efficient than AC lines if the transmission line length is not large enough. In Section 5.1, Tables 1 and 2 compare different approaches for efficiency improvement \& loss reduction approaches. 


\section{DISTRIBUTION LOSSES}

Distribution system losses are estimated to be greater than transmission system losses [35]. ABB states that combined transmission and distribution losses correspond to about $6 \%$ of the total electricity that is transmitted and distributed in the U.S. from 2001 to 2005 [36]. EIA also estimates that total combined losses correspond to $6 \%$ of the total electrical energy on average from 1990 to $2012 .{ }^{11}$ A dataset from World Bank further verifies that total losses amount for $6 \%$ in both 2010 and $2011 .^{12}$ This section highlights several of the loss mechanisms, and assesses options for improvement. In Section 5.1, Tables 1 and 2 compare different approaches for efficiency improvement $\&$ loss reduction approaches. In this section, we categorize the mechanisms under the headings Distribution Lines, Transformers, and Systems.

\subsection{DISTRIBUTION LINES}

Power is distributed by underground cables and overhead lines. Both of these are susceptible to losses, which produce heat in the conductors [37]. Broadly speaking, as the distance to the load increases, the amount of losses will increase. However, the amount of current carried in a given feeder decreases as the distance from the substation increases, because the load is distributed along the length of the system.

Underground cables are increasingly used because they are less susceptible than overhead lines to weather destruction and they reduce tree maintenance costs. However, they are more costly to install and less efficient to operate. A study in Wisconsin determined that construction of underground transmission cables can be from 4 to 14 times more expensive than overhead lines [38]. Other studies show lower costs but corroborate how installation costs increase with the use of underground cable. Underground cables contain a solid dielectric insulation and a metallic shield; they have loss mechanisms that have no counterpart in overhead lines. The loss mechanisms are conductor loss, dielectric loss, reactive current, and sheath loss.

(1) Conductor losses are the same in principle as discussed previously for transmission lines. A difference is that because the load is distributed, it is common practice to use smaller conductors further from the substation. The practice is called "tapering" the conductor.

A way to reduce conductor losses would be to use copper instead of aluminum for the conductor. Copper has a lower resistivity than aluminum. Therefore, it would have lower losses for any value of current, if it were the same cross section. However, copper is much more expensive than aluminum.

(2) Insulation is part of any conductor system. For overhead lines, air acts as the insulator, but for underground cables extruded dielectric materials are commonly used for insulation. (Some cables with oil-impregnated paper dielectric are still in service, too.) The voltage applied to the conductors stresses the insulation, and a small loss current may be produced. However, this current is typically so small that it is neglected. A loss-current above some threshold is used as a diagnostic for a cable problem. Dielectric losses are normally small enough to be neglected.

In underground cables there is another current due to the capacitance formed between the phase conductors and the sheath. For short-distance cables, this current is negligible, but for longer cables, the current (called a reactive current because it is out of phase with the voltage) can consume much of the current carrying capability of the cable [39]. While the out-of-phase current does represent power loss in the dielectric, it may cause considerable $I^{2} R$ loss in the conductor. The effect of the reactive

\footnotetext{
${ }^{11}$ http://www.eia.gov/tools/faqs/faq.cfm?id=105\&t=3 (accessed February 2014)

12 http://data.worldbank.org/indicator/EG.ELC.LOSS.ZS (accessed February 2014)
} 
current in cables can be mitigated by placing a reactor, an inductive element, in parallel with long cables. However, this costly measure is rarely needed in distribution systems because the lengths are relatively short.

The sheath around the cable is a grounded conductor used mainly to keep moisture out. It has the effect of keeping the electric field inside the insulation. The sheath does not normally have current flowing through it. (However, in some new cable constructions, used for single-phase loads, the neutral conductor is concentric, and carries the full return current.) The magnetic field of the phase conductors induces an eddy current in the sheath, and this eddy current causes a loss in the sheath. The magnitude of the loss was originally estimated [40] as significant, but a recent textbook [40] corrects earlier work and judges the effect minor. In any event, sheath loss is an unavoidable aspect of underground cables, and offers no practical route to loss reduction.

The driving force for installing underground cables is that they increase power availability during weather emergencies, reduce weather related maintenance costs, reduce tree maintenance costs, and improve aesthetics in neighborhoods by eliminating overhead lines.

Overhead lines are much less expensive per foot than underground cables, and allow for easier fault location. Overhead lines have been the primary method for distributing electricity in the United States. They have fewer loss mechanisms than underground cables. There is no sheath (and hence no sheath losses), and as with transmission lines, the proximity effect is negligible because the conductors are widely separated. At the voltages in use for distribution (sometimes referred to as Medium Voltage), corona effects are negligible unless there is a problem of some kind with hardware. As it is the case with the transmission conductors, $\mathrm{I}^{2} \mathrm{R}$ losses dominate the total resistive line losses. If the distribution voltage is increased by $10 \%$ for the same amount of load power, total losses decrease by $17.3 \%$.

\subsection{TRANSFORMERS}

Distribution transformers constitute a large fraction of the assets of the distribution infrastructure and account for a large part of the losses in the distribution system. According to the Energy Conservation Standards for low-voltage dry-type distribution transformers, the typical efficiency of distribution transformers varies 97.7 to $98.9 \%$. $^{13}$ Therefore, it can be stated that transformer losses correspond to about $2 \%$ of the losses in distribution systems. The importance of the matter has long been known, and DOE has been active in the area. In addition to funding studies and research, DOE has promulgated new regulations, 78 FR 23335, setting efficiency standards for transformers. These regulations are estimated to save about \$13bn, beginning in 2016. In the long term, the regulations will save about 3.6 Quads and avoid more than 260 million tons of carbon dioxide by 2045 [42].

Transformer losses are categorized into two types, load and no-load [43]. Load loss is a function of the amount of load the transformer is supplying: it is the combination of $\mathrm{I}^{2} \mathrm{R}$ loss in the windings and eddy currents caused by leakage flux: primarily it is winding loss. No-load losses are principally hysteresis and eddy current losses in the ferromagnetic core lamination; one paper asserts that these account for $99 \%$ of the no-load losses [44]. Reduction of these various losses can be done in several ways. All have been extensively studied, and aspects of transformer design and transformer materials are constantly improving. Details such as the gap size between strips in the transformer core and elevating the annealing temperature of the transformer core during manufacturing have been investigated [43]. Even minor effects such as dielectric losses (which make up less than $0.5 \%$ of the no-load losses), losses in core clamps, bolts and components (which make up less than $0.35 \%$ of the no-load losses), and $\mathrm{I}^{2} \mathrm{R}$ losses associated with

${ }^{13}$ http://www1.eere.energy.gov/buildings/appliance_standards/product.aspx/productid/66 (accessed February 2015) 
the no-load current ( $0.15 \%$ of loss) are under study [44]. No-load losses are important because they occur 24 hours a day, and they can exceed load losses in total energy [45]. Based on real transformer specification, the typical no-load losses for a $1500 \mathrm{kVA}$ distribution transformer are $5 \mathrm{~kW}$ while the maximum load losses are around $12 \mathrm{~kW}$ as shown in Figure 4 [46]. Furthermore, many modern MW level power transformers operate at $~ 98 \%$ efficiency (ABB Megawatt Station, PVS800-MWS 1.25MW). This efficiency is very high as compared to the transmission and distribution lines and indicates that there may be limited room for improvement in transformer efficiencies.

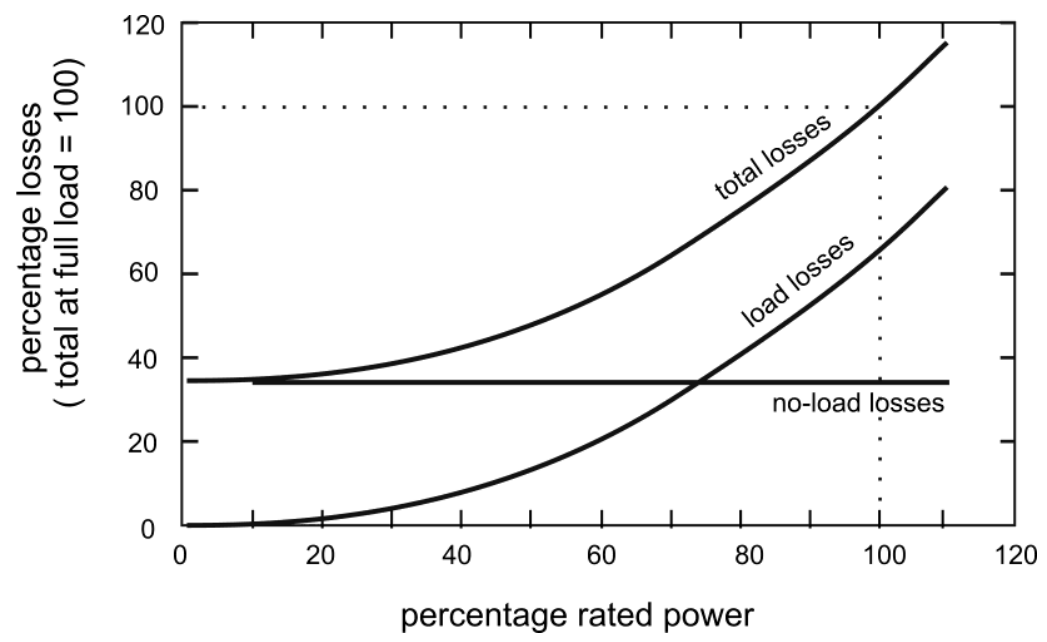

Figure 4. Percent of total possible losses of a typical $1500 \mathrm{kVA}$ distribution transformer. Source: Ref. [46]

However, most of the distribution loss analysis work has been with the assumption of resistive loads. Non-linear loads are becoming more important with the increasing use of power electronics. Correction of the effects of non-linear loads will be discussed later in the chapter. There are some studies showing that the harmonic distortions increase the distribution losses [47]. Addressing loss by reducing the distortion (possibly by monetizing it) or by re-designing the transformers is an area that may warrant further investigation. The metrology is difficult, and at this point in time the accuracy of commonly-used meters at off-nominal frequencies is not known.

\subsection{OTHER OPPORTUNITIES TO REDUCE DISTRIBUTION SYSTEM LOSSES}

There are several methods that could help reduce distribution system losses, in addition to those discussed above. Many of these methods have been studied under the general name of distribution automation, but they are not widely adopted, largely because of inadequate command and control infrastructure [48]. The coming smart grid may present opportunities to make measurements and perform calculations that could allow loss reduction.

\section{Load management}

Reduction of peak loads by active or passive load control has typically been thought of as a way to ease generation limits. However, it is also emerging as a way to reduce losses [49]. For loss-reduction, the area affected may be small, and it may good enough to ensure diversity between loads: if one house has the air-conditioner compressor running, the neighbor might be encouraged to wait. The topic of load management has been studied for over 20 years [50]. Since demand response can reduce the line load and thus the line current, it can reduce the transmission and distribution losses [51], especially during peak demand periods. 
Related to load management is the option of installing distributed generation. When on-board distributed generation systems are used (wind, solar, etc.), a portion of the power demand can be supplied locally from the distributed generators, instead of getting the entire load demand from the grid. As a result, this reduces the amount of power that needs to come through the transmission and distribution lines from the central generators [35]. Standards and recommended practices for incorporating distributed energy resources to the grid are organized under the Institute of Electrical and Electronics Engineers (IEEE) 1547 series of standards for interconnection and interoperability [52]. The main role of IEEE 1547 is to ensure that every generator, energy storage system, or renewable energy grid interconnection system meets the grid power quality requirements.

, Since DR can reduce the overall distribution system load, it can be stated that distributed generators including storage can reduce the transmission and distribution load and as well as the losses. However, distributed generation and demand response do not involve changes to infrastructure or operation of transmission and distribution system so they are out of the scope for this document.

\section{Reconfiguration}

System reconfiguration in real time can be used to unload a heavily-loaded line. System reconfiguration could end the practice of tapering the lines further from the substations, hence improving efficiency. However, it would require the addition of controllable sectionalizers, equipment that separates distribution feeder into sections to isolate a fault, and the equipment for monitoring them.

Other than unloading the heavily loaded lines, another system reconfiguration method is to use more transformer locations. This would result in shorter low voltage lines. However, for the most part, these lines are already short, as pole-top transformers are widely used. The figure below shows at least 4 poles in a row with three-phase transformers.

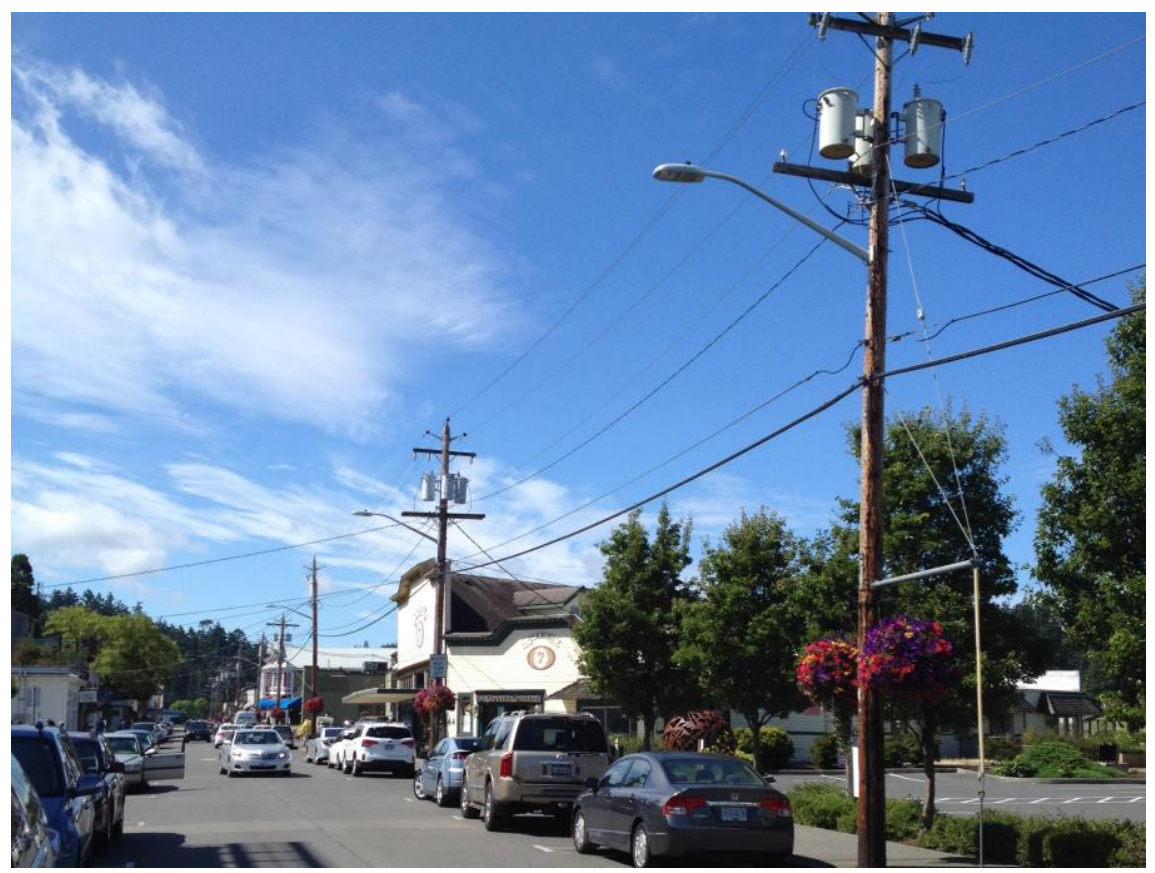

Figure 5. Street Scene, August 2014, Pacific Northwest. (Photo by H. Kirkham, PNNL)

It is theoretically possible to use three-phase lines instead of single phase for distribution. This would distribute the load over three conductors instead of one, reducing the loss. However, most distribution is 
already three phase (see photograph) on the high side of the transformer, and few loads are three-phase on the low side. U.S. low-voltage is typically done using a single phase center-tapped $240 \mathrm{~V}$ secondary providing two separate $120 \mathrm{~V}$ feeders that can be connected in series to provide $240 \mathrm{~V}$.

\section{Load Balancing}

During the design and construction of a typical distribution system, the number of connections to houses on a feeder will be balanced between each of the three phases. If the circuit is new, the load for each house is not known, but it is reasonable to assume that houses in a neighborhood will have similar consumption patterns.

Once those connections are made, it is extremely unlikely they are ever reviewed. Over the years, as customers change and add equipment, what was once a fair balance may no longer be. One customer could add refrigeration equipment that was not originally included, for example, or a number of domestic customers could all unknowingly add pool pumps on the same two phases. As a result, there could be a large current in the neutral. There are two effects: first, there are increased losses in the neutral wire, and second, there are increased losses in the distribution transformer. Each of these conditions can be mitigated. According to a system loss reduction study [53], increasing the phase imbalance from 0 to $15 \%$ increased the line losses of a test case distribution system from $\sim 80 \mathrm{~kW}$ to $100 \mathrm{~kW}$, which corresponds to an increase of $25 \%$. The same study reveals that $\mathrm{kW}$ losses of a distribution line increases exponentially with the $\%$ of the phase imbalance. For instance, $37.5 \%$ phase imbalance increases the line losses from $\sim 80 \mathrm{~kW}$ to $\sim 150 \mathrm{~kW}$ which corresponds to about $87.5 \%$ increase.

Consider first the neutral wire. Loads vary in a daily and weekly cycle. It is difficult to balance customer load across phases in real time. Long-term optimization is necessary to determine what load to put on what phase [55] . It should be possible, in principle, to survey the distribution system by measuring the neutral current. If the neutral current is unacceptably large, a more detailed study should reveal the problem. Algorithms could be developed that would allow a revised optimum solution to balance the load for a given feeder. At some suitable time, customers could be disconnected and reconnected to achieve better balance. This process has been researched for several years and neural network and heuristic methods have been studied with successful results [55]. These methods work by load balancing or switching done at the substation transformer and by phase balancing or switching along the laterals of a main feeder [55].

Note that the primary beneficiary in this process is not the customer. It may be that some customers might see a slightly better voltage at their point of connection, but it is most unlikely they will notice. The beneficiary will be the distribution company. This is due to the fact that for power calculation (metering), neutral current is not measured. In addition, for three-phase customers, there is no penalty for not balancing phases (unbalanced loading). Therefore, if the neutral wire is reconfigured, the distribution company benefits for reducing the neutral line losses.

Consider next the transformer. The load along a feeder is distributed and not coordinated, and while an assumption of phase balance may on average be a fair approximation, at any given time it is unlikely to be exactly accurate. At the supply end, the transformer sees imbalance, and its losses increase.

It is possible to move energy from one phase to another phase using power electronics. An example is shown in outline in Figure 6; it is an adaptation of the familiar full-wave three-phase converter. 


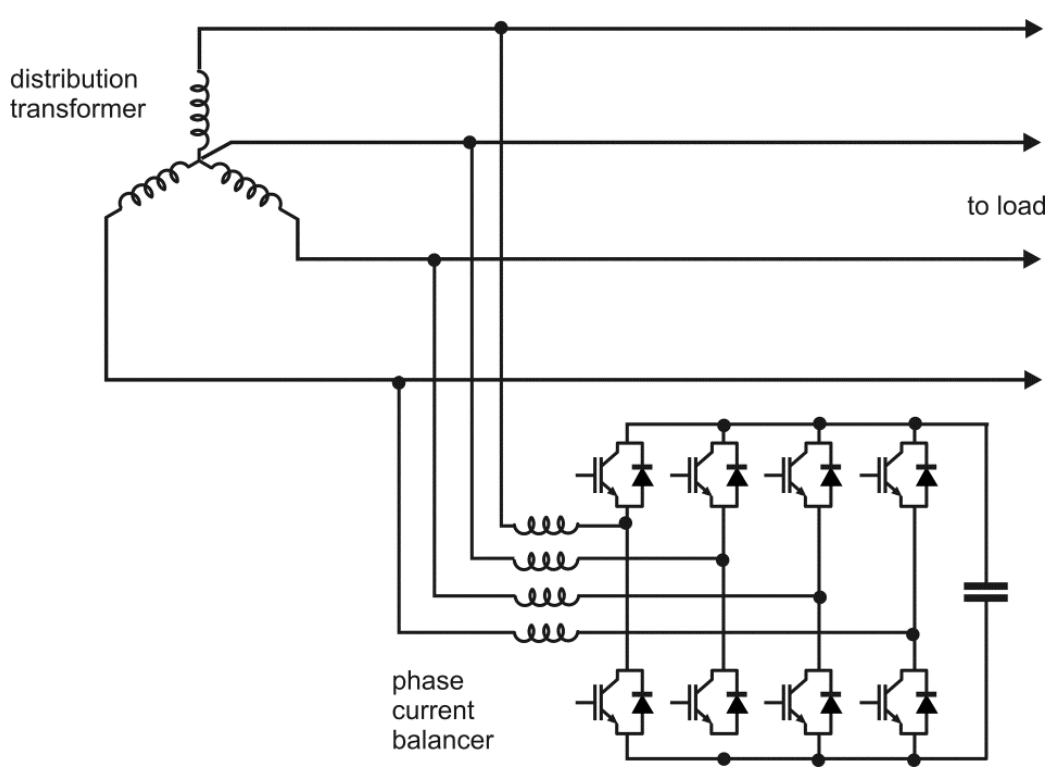

Figure 6. Phase-balance electronics. Source: Adapted from T. S. Win, E. Hiraki, M. Okamoto, S. R. Lee, and T. Tanaka, "Constant DC capacitor voltage control based strategy for active load balancer in three-phase four-wire distribution system," pp. 1560-1565 in Proceedings of 2013 International Conference on Electrical Machines and Systems, IEEE, 2013.

In this arrangement, the capacitor allows energy to be taken from one phase and applied a short-time later to another. The control system is designed to achieve balance in the phases at the distribution transformer, even though there may be a neutral current in the line.

Interestingly, the question of whether this is a correction of real or reactive power is unimportant. There is an IEEE standard that defines reactive power in balanced and unbalanced systems [56]. In fact, many definitions for reactive power are in use [57], and they converge on the same solution only under balanced and sinusoidal conditions. But reactive should surely be minimized in order to minimize the losses in delivering real power, and a device that achieves balance across phases is doing exactly that.

Whether or not it is economically worthwhile to construct a phase balancer of this kind is an unanswered question. Because power electronics is becoming more widely used and lower in cost, it may be that a system similar to this would be worth installing at some locations. However, as shown in a 2007 Northwest Energy Efficiency Alliance study, reducing phase imbalance from $25 \%$ to below $10 \%$ can reduce primary line losses by 10 to $15 \%$ [58].

\section{Increasing voltage class}

Distribution systems across the country are diverse in design. Some details are fairly common: most are radial, most are Medium Voltage. The radial design comes about not because of the cost of key factors such as the capital cost of building the lines, but also because of more subtle factors such as the cost of the protection system. Often, the choice of the voltage on the MV side of the transformers is a matter of history: once a company elects to use a certain voltage, considerable infrastructure is built to the company's standards.

Changing the standard would often result in a significant improvement in efficiency. While the voltage on the low-voltage side (say, 120 or 240 volts) is specified by regulations, the voltage above that is not, 
$14.7 \mathrm{kV}-24 \mathrm{kV}$. And as time has gone by and the load on the system has increased, the voltage on the MV side has generally not changed.

It is not possible to make a blanket statement about what fraction of distribution losses are due to the low voltage (LV) side and what fraction to the MV side, but since there are no options about changing the service voltage, it is worth considering changing the high-side.

Suppose that all the transformers in question could somehow be changed in ratio so that the MV side was operating at twice its present voltage. A $12-\mathrm{kV}$ system would be at $24 \mathrm{kV}$ and so on. If the load and the conductor were not changed, the current would be halved, and therefore the losses would drop by a factor of four.

The change could be done piecemeal across a system, so the cost could be spread over several years. In many instances, it would be possible to achieve this change without reconductoring. Most distribution systems are at low enough voltage that even doubling the voltage would not give rise to corona effects. Most ground clearances are not fixed by field effects at these voltages. It might be necessary to change the insulators, but that could be done by live-line work before the voltage was changed. Fuses would have to be replaced, surge arrestors if any, some circuit breakers, and of course, the transformers. The utility would recover its costs in the long term - the time depending on the starting voltage and the ending voltage.

This may be a useful area for future study. Given that simply doubling the MV voltage would leave a system no less uniform, it may be worth investigating the possible advantages of standardizing on one or two particular voltages. There are already considerable economies of scale in distribution hardware: For instance, having many different distribution voltage levels requires that several hardware components at different voltage ratings are manufactured in smaller amounts. However, for one or two standardized voltage levels, the production cost of distribution equipment would go down.

\section{More Efficient Substations}

Substations are the place where transmission voltage is converted down to distribution voltage. Substations consist of transformers, breakers, switches, and measurement devices. The main cause of losses in the substation is the transformers which have been discussed previously. However, another cause of losses is the location of the substation. If the substation is supporting load which is farther away then there will be more conductor losses, as explained before. However, by adding more substations closer to the load, the amount of conductor losses can be reduced. One way of achieving this, when it is not possible to place a large substation close to the load, is to install gas-insulated substations [36]. These substations take all the equipment needed for a substation and encase it inside a metal housing. The air is replaced with an inert gas, which reduces the risk of flashover for components within close proximity. These substations can be located in a confined space close to the load. This is another case where the utility companies have been optimizing placement of network components since the beginning of the power distribution grid. Economics will continue to drive the utilities to use improved substation infrastructure as technology provides those opportunities.

\section{Increasing Power Factor}

Power factor has been explained before with respect to the transmission system. Utility companies want to run the system at a power factor of 1 in order to make sure that all the power they are producing is being paid for by customers. As earlier mentioned, almost all utilities apply charges of penalties for reactive power consumption only for large customers. Most residential power factors are very high because there are two main types of major resistive behaving residential loads: heating and lighting. 
Heating loads absorb mostly active power and have a very high power factor, whereas cooling loads, fans or air conditioning i.e. motors, absorb mostly reactive power and have a lower power factor. However, the energy efficient cooling equipment on the market today has power factor correction technology or added capacitance to reduce the reactive current. Therefore, residential distribution power factor is not an issue for the distribution company.

Due to the use of heavy machinery, industrial equipment normally does not have good power factors. The figure below shows typical low power factor industries [59]. In most cases, the utilities charge industrial customers for the amount of real power they consume and add a surcharge or adjustment for power factor. However, most industrial power users install a shunt capacitor bank at their point of common coupling to increase the power factor and therefore, reduce their electric bill. The reduction in power costs will typically pay for this capacitor bank in less than 14 months [59].

\begin{tabular}{|c|c|}
\hline Industry & $\begin{array}{c}\text { Uncorrected Power } \\
\text { Factor }\end{array}$ \\
\hline Pulp and paper mills & $0.45-0.60$ \\
\hline Plastic (especially extruders) & $0.55-0.70$ \\
\hline Machine tools, stamping & $0.60-0.70$ \\
\hline Plating, textiles, chemicals, breweries & $0.65-0.75$ \\
\hline Hospitals, granaries, foundries & $0.70-0.80$ \\
\hline
\end{tabular}

Figure 7. Typical Low Power Factor Industries Source: Ref. [59]

\section{Conservation Voltage Reduction (CVR)}

Conservation Voltage Reduction uses automated distribution technology to lower voltage levels to improve efficiency. Two main benefits are reduction in annual energy consumption and reduction in the amount of peak load. TVA uses a feeder voltage feedback loop in its distribution system to bias voltage regulators to maintain the lowest acceptable feeder voltage. Year-round energy savings occur from enduse devices operating more efficiently at designed voltage levels. Some smart devices are achieving a $2.2 \%$ average energy reduction and a $1.8 \%$ peak load reduction from CVR [60]. Pacific Northwest National Laboratory (PNNL) found that CVR provides peak load reduction and annual energy reduction of approximately $0.5-3 \%$ [61]. In some cases, we have constant resistor - based loads. Therefore, applying a smaller voltage reduces the power that needed to be delivered (hence the current). But this is only done for peak reduction and it is not a permanent/continuous solution for loss reduction. In addition, although we had constant-resistance based loads historically dominating (electric heaters, light bulbs, ovens, etc.), now, due to recent technological advancements, we now have more constant power based loads with switched mode power supplies; for instance, laptop and cell phone adapters, LED/LCD TVs, DVRs, modern appliances that use variable frequency or adjustable speed drives such as air conditioners, heat pumps, and washing machines. For the constant power based loads, CVR is not effective because reducing the voltage does not reduce the power or current, instead, in order to maintain the power, line current increases, resulting in higher line losses. In addition, National Rural Electric Cooperative Association did a study for DOE and determined that Volt/VAR optimization using power factor correction was a better method to reduce losses than CVR using active voltage regulation based on efficiency improvement / loss reduction [55]. The paybacks to the utility were seen in the 0-2 year range which is a relatively short period of time for such an investment as opposed to CVR which has relatively longer payback time. In fact, with reactive power compensators, injecting reactive power increases the voltage whereas absorbing reactive power reduces the voltage at the point of common coupling with the compensator and the rest of the system. Since voltage can be controlled through Volt-VAr optimization, 
performing CVR at the generator busses is not really preferred. On the other hand, if CVR is accomplished at the substation level which feeds multiple feeders, then the cost of implementation could be reduced and payback period would be drastically reduced compared to active regulation.

According to a distribution efficiency initiative that was commenced in 2003 by the Northwest Energy Efficiency Alliance and completed in 2005, an average of $0.8 \%$ energy savings has been obtained for each $1 \%$ voltage reduction, performed by 13 utility companies

\section{Maintaining Power Quality}

Power quality is an expression to characterize disturbances in frequency and amplitude which are caused by the presence of negative and zero-sequence components, distributive generation, and harmonic components. Some of the newest causes of power quality reduction are the use of non-linear loads such as inverters for renewable energy and electric vehicles. The inverters inject harmonics from the switching of the power electronics converting DC to AC.

One method of improving the power quality of these non-linear loads is to apply an active power filter system to remove the harmonics that are injected from the inverter [62]. The active power filter can improve efficiency by reducing switching losses, has flexible selecting of harmonic order to eliminate depending on inverter type, and reduce the total harmonic distortion (THD) which is an indication of how the sinusoidal waveform is distorted [62]. Newer inverters can be utilized as a power convert to inject power generated from renewable energy sources to the grid and as a shunt active power filter to compensate for current imbalance, load current harmonics, load reactive power demand, and load neutral current [40]. This increases the power quality produced by the renewable energy sources.

\subsection{SUMMARY}

There are a greater number of potential efficiency losses in distribution systems than in transmission systems, as well as a greater number of technologies for dealing with these potential losses. Distribution lines present a paradox of efficiency losses; while overhead distribution lines experience little efficiency loss, underground distribution lines experience notable losses without any clear technical solutions. Distribution transformers, by contrast, exhibit notable efficiency losses both when experiencing load (losses due to winding loss) and in absence of load (losses due to hysteresis and eddy currents). Efficiency of transformers continues to be extensively researched by EPRI and DOE. Several interesting options emerge at the system level, including reconfiguration, load management, load balancing, and increasing voltage class. Reconfiguration and load management may require expanded control and measurement technologies, and load balancing may involve significant inconvenience to consumers as their distribution connections are interrupted during modification. Piecemeal elevation of a distribution grid's voltage status, for example by modifying transformers one-at-a-time, is an interesting and somewhat flexible option for enhancing the distribution grid's efficiency. In Section 5.1, Tables 1 and 2 compare different approaches for efficiency improvement \& loss reduction approaches. 


\section{TECHNOLOGY CHARACTERIZATION and OPERATIONAL STRATEGIES}

Losses in the transmission and distribution system can arise from a variety of phenomena. There are many strategies for addressing these phenomena, which can generally be categorized into passive strategies, active strategies, and planning and management strategies.

Passive strategies involve installing new equipment with intrinsic design or material composition that will reduce losses over existing or other kinds of designs or materials. These include many of the strategies for reducing resistance of transmission or distribution lines and cables, such as reconductoring with material (e.g., super conductors, copper, choice of material for sheath) or designs (e.g., conductor spacing) that reduces resistance. Losses from skin effect can be reduced by using certain shapes of conductor (trapezoidal width) and by shortening line length by installing more transformers. Some strategies for reducing current (increasing voltage class, locating generators closer to loads, installing shunt capacitor banks near reactive loads and at substations) are also passive strategies. The design and choice of material used in distribution transformers can also reduce losses, as can adding filters to remove harmonics and right-sizing equipment to balance load and no-load losses [63].

Active strategies enable operators to operate the system in ways that can reduce losses. They can involve installing or investing in new transmission or distribution equipment, communications equipment, or control capabilities. ${ }^{14}$ Many active strategies can reduce current on lines or cables, which reduces losses. These include the various ways of controlling power flow, such as controlling voltages with generator output, tap-changing transformers, switching capacitor banks and other reactive power devices. FACTS devices can change effective impedance of lines and thus be controlled in ways to redirect flow in order to reduce losses. At the distribution level, phase balancing and conservation voltage reduction are active strategies that are being pursued by utilities [63]. Power systems operation and control decisions are typically made through running algorithms that determine controllable operating points, including generator dispatch as well as optimal control and setting levels for this equipment [64]. Any implementation of active strategies must include control decision mechanism, communication and control of equipment, and in some cases coordination with neighboring systems.

Finally, planning and management strategies enable construction and operation of a system in ways that reduce losses. Generation dispatch algorithms, when programmed to include transmission losses, optimally determine which generators will meet load taking into account the generation that will be lost in the transmission system (generally optimal power flow does not take into account how power is consumed or lost in the distribution system). Losses will not necessarily be minimized, but overall power system operation - including the amount of power generated that will be lost in the transmission - will be optimized for least-cost dispatch [65]. ${ }^{15}$

Other operation and planning activities can be performed in ways that minimize losses. These include incorporating new technologies, such as electric vehicle charging, in the dispatch algorithm; [66] planning

\footnotetext{
${ }^{14}$ The distinction between passive and active strategies being made here is that passive strategies reduce losses without taking any further operational actions. Active strategies require action by operators or automated control systems. It possible some passive strategies could be enhanced by pairing it with active strategies, but this is not necessarily so.

${ }^{15}$ For example, there could be a situation where operation costs at a far-away generation plant are low, but transporting the power to load centers results in high losses. A closer plant may have higher operating costs but transporting its power results in fewer losses. If the total cost of producing power (consumption plus what is lost in transmission) at the distant plant is lower than the total cost of producing power (consumption plus what is lost in transmission) at the closer plant, then the least cost dispatch will minimize losses.
} 
decisions, such as where to locate generation (utility-scale or distribution) or other equipment; [67], [68] and providing economic incentives to customers, for instance by designing reactive power tariffs customers can be incentivized to improve management of their power factor (the relationship between real and reactive power) [63]. ${ }^{16}$

\subsection{MEASURING COSTS AND BENEFITS}

Decisions about whether to implement strategies to reduce losses in the transmission and/or distribution system should be made with knowledge of the costs and benefits of doing so. ${ }^{17}$ The costs and benefits can be measured from a system baseline forecast. The costs of a strategy include capital and installation cost of equipment, operations and maintenance expenditures, as well as the cost of developing and implementing new software or communication and control equipment.

Benefits of loss reduction strategies include direct cost savings from reducing electricity generated that is lost (e.g., less power is produced to meet same demand) and indirect or long-term savings from reducing the need for generation, transmission and distribution capacity. Direct cost savings depend on the amount of losses reduced and the avoided cost of producing that electricity; calculating this can be challenging because the value of reducing losses are associated with the cost of production at the time of the reduction. One industry-accepted method for calculating load and no-load losses from a distribution transformer simplifies this by using an annual rate of energy [69].

Indirect cost savings accrue to utilities that own transmission and distribution systems, and/or generation. Reducing losses will, incrementally and over time, reduce the need to expand the capacity of the transmission and distribution system to accommodate transmission of those losses, as well as the generation fleet to produce the extra power that is lost. This reduced need for new capacity reduces investment cost over time. These indirect savings may be more immediate when transmission, distribution or generation capacity is constrained [70].

It is difficult to calculate a generic cost/benefit value for loss reduction technologies or methods because each network situation is unique: loss reduction strategies will result in various amounts of loss reduction depending on system configuration and usage, and be valued at the particular power prices in each region. Cost/benefit analysis should be undertaken by particular utilities considering loss reduction investments to inform their specific decisions [70].

Replacing existing infrastructure for loss reduction purposes alone typically cannot be justified on economic grounds [71]. However, incorporating loss reduction considerations in the design or planning of new capacity or reliability investments being made for other reasons can have an impact on the benefitcost ratio of an investment [70]. ${ }^{18}$

In addition, the way a cost/benefit analysis is conducted, how the values are calculated or what costs and benefits are included may have an impact on how well the analysis reflects the actual likelihood of

\footnotetext{
${ }^{16}$ The power factor describes the relationship between current and voltage at any point in an alternating current system. This relationship is indicative of the type of load at that interconnection point: inductive loads are said to be "lagging" (current lags voltage); capacitive loads are said to be "leading" (current leads voltage). Inductive loads require more reactive power, which increases total line current that contribute to higher losses. Reducing the lag between current and voltage with capacitors or other equipment can lower the need for reactive power and, thus, losses.

${ }^{17}$ See [72] for more details on evaluating costs and benefits of transmission energy-efficiency options.

${ }^{18}$ Benefits could also include secondary factors such as avoided environmental compliance costs or power quality impacts.
} 
adoption. For instance, some studies calculate the engineering capability under idealized circumstances (e.g., no uncertainty, or perfect foresight of system conditions). This is valid as a way to put an upper limit on the potential impact.

Beyond the overall benefit-cost ratio, the distribution of costs and benefits are important considerations for policymakers. If the entity making the investment decision is not the same entity that would enjoy all the benefits, then the theoretical cost/benefit ratio may not reflect the economic realities of that entity, and policy or regulatory action may be needed in order to align incentives and allow cost-effective investments to be pursued. In addition, there may be institutional barriers to making investments with a favorable cost/benefit ratio: these are described further in the next section.

While general cost/benefit values are not widely available for particular loss reduction strategies, some observations are gathered here.

- In some situations, changing operations of an existing system, such as optimizing voltage set points, capacitor settings or switching, can generally be more economical than installing new equipment [70].

- $\quad$ Loss reduction with additional shunt compensation has been calculated in the range of 3.4 to 4.2 (benefit/cost) (range depends on aggressiveness of deployment) [73].

- Loss reduction from operating existing reactive controls using an optimal power flow (OPF) dispatch with the objective of minimizing losses (as opposed to total dispatch cost) has been calculated as high as 300,000 MWh/Year (i.e., in excess of $30 \mathrm{M} \$ /$ year). This was calculated as a benefit-cost ratio of 30 (benefit/cost) [73]. ${ }^{19}$

- A PJM report estimates up to $\$ 75$ million savings due to transmission line loss reduction per year from increasing voltage of a line from $345 \mathrm{kV}$ to $500 \mathrm{kV}$ [74]. ${ }^{20}$

\subsection{CROSS-CUTTING, INSTITUTIONAL ISSUES}

In addition to economic factors, certain institutional issues also play into whether companies adopt lossreduction strategies, and what barriers exist to wider adoption. These include regulatory factors such as permitting and siting of new lines or other equipment.

States, and in some cases local bodies, have significant authority in the permitting and siting of new transmission and distribution equipment or upgrading existing equipment.

New transmission: The process for permitting and siting new transmission lines in new right-of-way corridors can be difficult and lengthy. New routes for transmission lines may not be the shortest or least expensive because they have to take into account local stakeholders who may object to routes based on

\footnotetext{
${ }^{19}$ This result was from a study that simulated an OPF dispatch. The calculated benefits should be seen as an upper limit on the possible loss savings. Two factors make this an optimistic assumption: one is that operators rarely dispatch their system solely to minimize losses; and two the control of equipment is tuned to exact operating conditions. If the operating setting on the controllable equipment was decided prior to real-time and some unexpected change occurred (e.g., an outage) the controllable equipment may not be set to operate at the greatest loss reduction.

${ }^{20}$ Assuming a consistent 2,000 MW flow over 100 miles.
} 
other attributes (e.g., environmental). ${ }^{21}$ State and local governments have jurisdiction over siting, but the actual agencies involved and permitting rules vary from state to state [75], [76], [77], [78]. If multiple states are involved there are multiple procedures to follow, priorities and schedules can be unclear, thus extending the time it takes to successfully move a project forward, and increasing the difficulty of advancing the project. Complications can also arise from having multiple planning entities that are not coordinated, who may propose multiple different plans with no clear way of reconciling.

New equipment in existing rights-of-way (ROW): There are several ways of increasing throughput on an existing ROW, including dynamic line ratings, reconductoring and increasing the voltage of a circuit. In some cases, dynamic line ratings and reconductoring (with high-temperature low-sag conductors) can increase losses because current throughput is increasing without other characteristics changing (e.g., operating voltage, conductor resistance) [79]. Increasing the voltage of an existing corridor can be challenging because existing tower configuration can limit how high the voltage can be; thus increasing voltage could involve constructing new towers (which would increase project cost) and/or expanding the width of the ROW. Changing or establishing new rights of way can a challenging institutional process.

Regulatory issues: Transmission- and distribution-owning utilities are generally regulated companies that must have their investments approved by a regulatory body, typically the state utility commission, or in some cases a federal entity. This includes investments in, or incremental costs for, reducing losses on the transmission or distribution system. In some states, T\&D system improvements can be credited toward compliance with a state energy efficiency resource standard (EERS). Therefore, in these states it is easier to justify the T\&D improvement benefits whereas the majority of states choose not to include the improvement costs credited towards EERS compliance [80]. One challenge to incentivizing efficiency in the transmission and distribution system is there are no standard measurement and verification protocols for these loss reductions, though some are under development. Because it is difficult to measure loss reduction in a comparable or standard way, utilities may have difficulty quantifying and verifying the savings from programs in order to justify cost recovery or participation in efficiency programs (where possible) in the same way end-use efficiency programs do [81].

\footnotetext{
${ }^{21}$ Utilities negotiate with landowners to compensate them for use of their land, or to outright purchase their land, but even still local stakeholders may not be satisfied with economic compensation in exchange for not opposing a new transmission line path.
} 


\section{SYNTHESIS: WHAT EFFICIENCY IMPROVEMENTS ARE POSSIBLE}

Existing research features two approaches to quantifying efficiency potential: Estimating what efficiency improvements are physically possible, and what efficiency improvements are cost-effective under existing institutional structures. Conducting a study to determine the nationwide potential of all cost-effective T\&D efficiency practices could be a valuable, but major, effort. While no such study currently exists, studies on specific regions and specific technologies can inform our understanding of the magnitude of national potential.

Some estimates of loss reduction potential have been calculated in the literature.

- Conservation voltage reduction (CVR) may be an effective way of reducing end-use demand, it does not provide significant loss reduction [82]. ${ }^{22}$ In fact, while it can reduce the overall energy demand and can result in energy savings, it does not necessarily reduce the losses; particularly for the systems with constant power based loads [83]. According to a distribution efficiency initiative that was commenced in 2003 by the Northwest Energy Efficiency Alliance and completed in 2005, an average of $0.8 \%$ energy savings has been obtained for each $1 \%$ voltage reduction, performed by 13 utility companies. Although for constant resistance loads, this also reduces the line losses, for constant power loads this means more current is needed which actually increases the line losses. Today, enduser loads are a mix of constant power (devices with switched mode power supplies, computers, some appliances, etc.) and constant resistance loads (heaters, light bulbs, ovens, dryers, etc.).

- Tests of Volt-VAr Optimization (VVO) on a small number of feeders in the Sacramento Municipal Utility District found potentially small amount of loss reduction [81]. According to a report from Weikert [84], VVO application can potentially reduce the overall distribution line losses by $2-5 \%$. On the other hand, local reactive power compensation at the end-user side, can reduce the line current by $15 \%$ and line losses by $28 \%$.

- The U.S. DOE estimated that the implemented standards for liquid-immersed, low-voltage dry-type and medium-voltage dry-type distribution transformers would save 0.92, 2.43 and 0.29 quads between 2016 and 2045, respectively. ${ }^{23}$ Higher efficiencies for these three types of transformers were studied (but not adopted as standards because they were not found to be economically justifiable) were shown to save up to $7,4.9$ and .84 quads, respectively [42] ${ }^{24}$ Companies could choose to install these high efficiency transformers.

- A theoretical examination of the effect of feeder reconfiguration and capacitor installation on a model of two distribution systems (252-node and 168-node) found losses reduced by $28 \%$ in each [76]. Another study in 2001 found $3.38 \%$ to $11.70 \%$ loss reduction through feeder reconfiguration for four different test cases [85]. A more advanced software algorithm, "Tabu Search" has been used in a 2009 study [86] that showed as much as $54 \%$ to $58 \%$ loss reduction can be achieved from feeder reconfiguration.

\footnotetext{
${ }^{22}$ Other studies, however, have suggested that CVR can reduce no-load losses in transformers [56]. More research in this area may be useful.

${ }^{23}$ This corresponds to a total projected 30-year savings of nearly 270 million, 712 million and nearly 85 million MWh, respectively, and an annual average of nearly 9 million, 24 million and 3 million MWh. Total electricity consumption in the U.S. in 2012 was 3.7 billion MWh, or 12.6 quads. (Source: EIA 2012 Electric Power Annual)

${ }^{24}$ This corresponds to a total projected 30-year savings of nearly 2 billion, 1.4 billion and nearly 246 million MWh, respectively, and an annual average of 68 million, 48 million and 8 million MWh.
} 
- A theoretical study of optimization of capacitor settings and distribution reconfiguration specifically for loss reduction on a simulated 119-bus distribution network achieved loss reduction of 40\% [87].

- Another theoretical study of shunt capacitor installation placement found up to $40 \%$ loss reduction compared with a system with no capacitors, for a very small distribution test system [88]. Weikert [84] also confirms this finding with a $30 \%$ potential loss reduction through local reactive power compensation with shunt capacitors.

- A 2009 EPRI report gathered estimates of possible loss reduction from a variety of loss reduction strategies [81].

$\circ$ Raising transmission line voltage: $>50 \%$ loss reduction in upgraded line

○ Implementing VAR/Voltage profile optimization: $1-5 \%$

- Reconductoring with trapezoidal width conductor: up to $20 \%$ (replacing line of equal diameter)

○ Bundling with same conductor: up to $50 \%^{25}$

- According to Green Circuits: Distribution Efficiency Case Studies Report from EPRI-Palo Alto [89], the energy savings are more significant in the U.S. For instance, phase balance + VAr optimization + re-conductoring results in 3.9\% energy savings, only phase balancing results in $3.6 \%$ energy savings, phase balancing + var optimization results in 1.3 to $2.3 \%$ energy savings, and voltage regulators result in $1.9 \%$ to $2.6 \%$ energy savings.

\subsection{SUMMARY OF STRATEGIES}

Tables 1 and 2 summarize the sources of transmission and distribution losses and loss reductions reviewed in this document. They highlight the wide array of options available to improve the efficiency of the U.S. T\&D system. Among several options, reconductoring, use of superconductors, controlling power flow (i.e., through FACTS systems), HVDC are the possible options for transmission loss reduction strategies. Regarding the corona loss reduction, although voltage reduction is the easiest method, the drawback is increased line current that would also increase the line losses. Therefore, the tradeoff between the Corona related losses and the ohmic losses should be well examined. Through the reconductoring, incremental loss reductions of $30-70 \%$ is possible; however, it increases the material cost and the weight of the conductors; therefore, mechanical structure of the transmission line might be redesigned. Superconductors can also reduce the transmission losses up to 50\%; however, superconductors that can operate at ambient temperatures are still at the development stage. FACTS and other power electronics based shunt connected solutions may be the most feasible options since they are not designed to take the entire system power (not connected in series to carry the entire load) and they can effectively provide active phase balancing, reactive power compensation, power factor correction, and voltage control; however, the cost of FACTS systems are still relatively high and the design of power electronic converters at high power levels is still a challenge. HVDC is another option for transmission loss reduction; however, it is also a costly solution and involves power electronic converters that can operate at transmission level high power ratings. Additionally, HVDC is cost effective only for long transmission lines.

\footnotetext{
${ }^{25}$ Bundling requires reinforcing the transmission line structures (e.g., towers); thus bundling is only cost effective if reinforcing the structures is economical.
} 
In the distribution system, loss reduction opportunities are greater. Load management can provide loss reduction of 8 to $20 \%$ whereas distribution system management provides an estimated $7.2 \%$ loss reduction through the optimal power flow control. Line reconfiguration can provide 5 to $20 \%$ loss reduction while load balancing can also reduce the distribution system losses by the same rate. If the power factor is corrected on distribution lines, there is a potential loss reduction of $30 \%$. Furthermore, increasing the rated voltage of the distribution system provides a loss reduction of 40 to $75 \%$. These transmission and distribution system loss reduction opportunities are summarized in Tables 1 and 2.

Table 1. Transmission Losses

\begin{tabular}{|c|c|c|c|c|c|}
\hline & Key Advantage & Key Drawback & Key Uncertainty & $\begin{array}{l}\text { Restrictions on } \\
\text { Application }\end{array}$ & $\begin{array}{c}\text { Loss } \\
\text { Reduction }^{a}\end{array}$ \\
\hline \multicolumn{6}{|l|}{ Transmission Losses } \\
\hline \multicolumn{6}{|l|}{ Ohmic Loss } \\
\hline Reconductoring & $\begin{array}{l}\text { enable } \\
\text { incremental } \\
\text { reductions in } \\
\text { ohmic loss }\end{array}$ & $\begin{array}{l}\text { incremental } \\
\text { increase in } \\
\text { materials cost; } \\
\text { possible large cost } \\
\text { of system redesign }\end{array}$ & little & none & $30-70 \%{ }^{b}$ \\
\hline Superconductors & $\begin{array}{l}\text { enable large } \\
\text { reductions in } \\
\text { ohmic loss }\end{array}$ & $\begin{array}{l}\text { large materials cost } \\
\text { increases; subject } \\
\text { to inefficiencies } \\
\text { from underground } \\
\text { systems }\end{array}$ & $\begin{array}{l}\text { level of } \\
\text { inefficiency } \\
\text { experienced by } \\
\text { undergrounding } \\
\text { the superconductor }\end{array}$ & $\begin{array}{l}\text { available to } \\
\text { underground } \\
\text { systems only }\end{array}$ & $\sim 50 \%^{c}$ \\
\hline $\begin{array}{l}\text { Controlling Power } \\
\text { Flow, e.g. Via } \\
\text { FACTS systems }\end{array}$ & $\begin{array}{l}\text { no need to change } \\
\text { materials on } \\
\text { distribution } \\
\text { systems }\end{array}$ & $\begin{array}{l}\text { new control } \\
\text { technologies } \\
\text { required, at cost }\end{array}$ & $\begin{array}{l}\text { how to implement } \\
\text { new control } \\
\text { technologies } \\
\text { (BPA a lead } \\
\text { example) }\end{array}$ & none & $\sim 50 \%^{d}$ \\
\hline $\begin{array}{l}\text { High Voltage Direct } \\
\text { Current (HVDC) }\end{array}$ & $\begin{array}{l}\text { can increase } \\
\text { system voltage }\end{array}$ & $\begin{array}{l}\text { requires new } \\
\text { inverters and } \\
\text { power system } \\
\text { engineering for } \\
\text { integration into AC } \\
\text { grid }\end{array}$ & $\begin{array}{l}\text { net impact on } \\
\text { efficiency unclear; } \\
\text { may be less } \\
\text { efficient than AC } \\
\text { transmission }\end{array}$ & $\begin{array}{l}\text { rights-of-way } \\
\text { procurement }\end{array}$ & $\begin{array}{l}10-20 \% \text { (only } \\
\text { for long distance } \\
\text { lines) } e^{e}\end{array}$ \\
\hline $\begin{array}{l}\text { Reactive power } \\
\text { compensation / } \\
\text { power factor } \\
\text { improvement (also } \\
\text { provides voltage } \\
\text { regulation and } \\
\text { control) }\end{array}$ & $\begin{array}{l}\text { can effectively } \\
\text { reduce the line } \\
\text { current, } \\
\text { eliminates } \\
\text { reactive power } \\
\text { circulation from } \\
\text { generation busses } \\
\text { to load busses }\end{array}$ & none & none & none & $\begin{array}{l}30 \% \\
20-80 \%, \\
\text { depending on } \\
\text { compensation } \\
\text { location }^{f}\end{array}$ \\
\hline
\end{tabular}


Table 1. Transmission Losses (continued)

\begin{tabular}{|c|c|c|c|c|c|}
\hline & Key Advantage & Key Drawback & Key Uncertainty & $\begin{array}{l}\text { Restrictions on } \\
\text { Application }\end{array}$ & $\begin{array}{c}\text { Loss } \\
\text { Reduction }^{a}\end{array}$ \\
\hline $\begin{array}{l}\text { Peak demand } \\
\text { reduction }\end{array}$ & $\begin{array}{l}\text { can effectively } \\
\text { reduce the current } \\
\text { during peak } \\
\text { demand periods }\end{array}$ & $\begin{array}{l}\text { needs demand } \\
\text { response or energy } \\
\text { storage systems } \\
\text { integration }\end{array}$ & $\begin{array}{l}\text { cost for energy } \\
\text { storage and end- } \\
\text { user flexibility for } \\
\text { demand response }\end{array}$ & $\begin{array}{l}\text { not directly related } \\
\text { to transmission } \\
\text { system } \\
\text { infrastructure }\end{array}$ & $0.8-2.4 \%^{g}$ \\
\hline \multicolumn{6}{|l|}{ Corona Loss } \\
\hline Voltage Reduction & $\begin{array}{l}\text { can reduce } \\
\text { Corona discharge }\end{array}$ & $\begin{array}{l}\text { can cause loss in } \\
\text { power quality }\end{array}$ & $\begin{array}{l}\text { when/where it } \\
\text { can be } \\
\text { implemented }\end{array}$ & $\begin{array}{l}\text { only available to } \\
\text { systems under low } \\
\text { load and certain } \\
\text { weather conditions }\end{array}$ & $10-40 \%^{h}$ \\
\hline $\begin{array}{l}\text { Anti-Corona material } \\
\text { coating of conductor }\end{array}$ & $\begin{array}{l}\text { Can significantly } \\
\text { reduce the } \\
\text { Corona discharge } \\
\text { and losses }\end{array}$ & $\begin{array}{l}\text { Not very practical } \\
\text { for existing } \\
\text { transmission lines, } \\
\text { might be used for } \\
\text { future installations }\end{array}$ & $\begin{array}{l}\text { Cost and } \\
\text { implementation } \\
\text { simplicity }\end{array}$ & $\begin{array}{l}\text { Cost, difficult to } \\
\text { implement in } \\
\text { existing systems, } \\
\text { might be heavy in } \\
\text { some cases }\end{array}$ & $\begin{array}{l}\text { Still at research } \\
\text { level, savings not } \\
\text { quantified yet }^{i, j}\end{array}$ \\
\hline \multicolumn{6}{|c|}{$\begin{array}{l}{ }^{a} \text { This column represents the estimates of potential transmission loss reductions within the specific kind of losses for each } \\
\text { proposed strategy. It does not represent an estimate for what proportion of the total transmission losses that could be reduced in } \\
\text { the U.S. using these strategies. Hence, these percentages should not be directly compared to one another, as the potential for loss } \\
\text { reduction varies by loss type. } \\
{ }^{b} \text { Carl Dombek "High-tech conductor could help Southern California in wake of SONGS closure: Conductor carries more current, } \\
\text { has lower line losses," Transmission Hub TM, June, } 2013 \text {. } \\
{ }^{c} \text { Jacob Oestergaard et al. "Energy losses of superconducting power transmission cables in the grid," IEEE Transactions on } \\
\text { Applied Superconductivity, } 11: 2375,2001 \text {. } \\
{ }^{d} \text { Peter Fairley "Flexible AC transmission: The FACTS machine, flexible power electronics will make the smart grid smart," } \\
\text { IEEE Spectrum Magazine, Dec. } 2010 \text {. }\end{array}$} \\
\hline
\end{tabular}


Table 2. Distribution Losses

\begin{tabular}{|c|c|c|c|c|c|}
\hline & $\begin{array}{c}\text { Key } \\
\text { Advantage }\end{array}$ & Key Drawback & $\begin{array}{c}\text { Key } \\
\text { Uncertainty }\end{array}$ & $\begin{array}{l}\text { Restrictions } \\
\text { on } \\
\text { Application }\end{array}$ & Loss Reduction $^{a}$ \\
\hline \multicolumn{6}{|l|}{ Distribution Losses } \\
\hline \multicolumn{6}{|l|}{ Distribution Lines } \\
\hline $\begin{array}{l}\text { Underground } \\
\text { Systems }\end{array}$ & - & $\begin{array}{l}\text { subject to } \\
\text { several } \\
\text { efficiency } \\
\text { losses }\end{array}$ & - & - & \\
\hline Overhead Systems & $\begin{array}{l}\text { more efficient } \\
\text { and suffer } \\
\text { from } \\
\text { fewer/lesser } \\
\text { categories of } \\
\text { loss }\end{array}$ & - & - & $\begin{array}{l}\text { may be } \\
\text { difficult to } \\
\text { acquire rights } \\
\text { of way in } \\
\text { urban areas }\end{array}$ & \\
\hline \multicolumn{6}{|l|}{ Systems Level } \\
\hline Load Management & $\begin{array}{l}\text { can reduce } \\
\text { losses by } \\
\text { reducing } \\
\text { delivery of } \\
\text { power over } \\
\text { grid during } \\
\text { peak times } \\
\text { (akin to } \\
\text { conservation) }\end{array}$ & $\begin{array}{l}\text { may require } \\
\text { new } \\
\text { technologies, } \\
\text { customer } \\
\text { enrollment }\end{array}$ & $\begin{array}{l}\text { the form of load } \\
\text { management } \\
\text { program, which } \\
\text { may also include } \\
\text { distributed } \\
\text { generation; } \\
\text { impacts on other } \\
\text { performance } \\
\text { aspects of the } \\
\text { grid }\end{array}$ & none & $8-20 \%^{b}$ \\
\hline $\begin{array}{l}\text { Conservation } \\
\text { Voltage Reduction } \\
\text { (CVR) }\end{array}$ & $\begin{array}{l}\text { can reduce } \\
\text { energy } \\
\text { consumption } \\
\text { and the } \\
\text { amount of } \\
\text { peak load }\end{array}$ & $\begin{array}{l}\text { may not be very } \\
\text { effective in } \\
\text { switched mode } \\
\text { power supply } \\
\text { based "constant } \\
\text { power loads" }\end{array}$ & $\begin{array}{l}\text { it may benefit } \\
\text { the system in } \\
\text { some cases } \\
\text { (where constant } \\
\text { resistance-based } \\
\text { loads are } \\
\text { dominating) } \\
\text { whereas it may } \\
\text { increases the } \\
\text { overall losses } \\
\text { (where constant- } \\
\text { power loads are } \\
\text { dominating) in } \\
\text { other cases }\end{array}$ & none & $\sim 2.2 \%$ \\
\hline $\begin{array}{l}\text { Volt/VAr } \\
\text { Optimization } \\
\text { (VVO) }\end{array}$ & $\begin{array}{l}\text { can reduce the } \\
\text { distribution } \\
\text { line losses and } \\
\text { can reduce the } \\
\text { losses } \\
\text { associated } \\
\text { with reactive } \\
\text { power delivery }\end{array}$ & $\begin{array}{l}\text { complexity in } \\
\text { implementation } \\
\text { and controls }\end{array}$ & $\begin{array}{l}\text { reactive power } \\
\text { could be locally } \\
\text { compensated } \\
\text { instead of } \\
\text { substation level } \\
\text { centralized } \\
\text { Volt/VAr } \\
\text { regulators }\end{array}$ & $\begin{array}{l}\text { cost if active } \\
\text { methods are } \\
\text { used }\end{array}$ & $2-5 \%^{c}$ \\
\hline
\end{tabular}


Table 2. Distribution Losses (continued)

\begin{tabular}{|c|c|c|c|c|c|}
\hline & $\begin{array}{c}\text { Key } \\
\text { Advantage }\end{array}$ & Key Drawback & $\begin{array}{c}\text { Key } \\
\text { Uncertainty }\end{array}$ & $\begin{array}{l}\text { Restrictions } \\
\text { on } \\
\text { Application }\end{array}$ & Loss Reduction ${ }^{a}$ \\
\hline $\begin{array}{l}\text { Distribution } \\
\text { network } \\
\text { management } \\
\text { (through optimal } \\
\text { power flow control) }\end{array}$ & $\begin{array}{l}\text { can effectively } \\
\text { reduce the } \\
\text { losses }\end{array}$ & $\begin{array}{l}\text { computer based } \\
\text { algorithms } \\
\text { work very well } \\
\text { but there is a } \\
\text { lack of } \\
\text { controllable } \\
\text { hardware that } \\
\text { can be used to } \\
\text { reroute or } \\
\text { control the } \\
\text { power flow }\end{array}$ & $\begin{array}{l}\text { implementation } \\
\text { cost, hardware } \\
\text { implementations } \\
\text { and integrity }\end{array}$ & cost & $7.2 \%^{d}$ \\
\hline Reconfiguration & $\begin{array}{l}\text { can reduce } \\
\text { losses from } \\
\text { overloading } \\
\text { specific lines }\end{array}$ & $\begin{array}{l}\text { new monitoring } \\
\text { and control } \\
\text { technologies } \\
\text { necessary to } \\
\text { implement } \\
\text { reconfiguration }\end{array}$ & $\begin{array}{l}\text { what kind of } \\
\text { technologies and } \\
\text { how to use them }\end{array}$ & $\begin{array}{l}\text { works better in } \\
\text { densely- } \\
\text { networked, } \\
\text { integrated } \\
\text { systems with } \\
\text { more lines } \\
\text { available for } \\
\text { reconfiguration }\end{array}$ & $5-20 \%{ }^{e, f}$ \\
\hline Load Balancing & $\begin{array}{l}\text { redistributes } \\
\text { distribution } \\
\text { grid } \\
\text { components to } \\
\text { meet changes } \\
\text { in demand } \\
\text { timing, } \\
\text { location, and } \\
\text { technology }\end{array}$ & $\begin{array}{l}\text { may require } \\
\text { interruption of } \\
\text { customer } \\
\text { services/other } \\
\text { inconvenience } \\
\text { to customer as } \\
\text { grid } \\
\text { connections are } \\
\text { redistributed }\end{array}$ & $\begin{array}{l}\text { the orientation of } \\
\text { demand to the } \\
\text { grid; audits } \\
\text { necessary to } \\
\text { determine, e.g., } \\
\text { appliances } \\
\text { installed, where } \\
\text { demand is } \\
\text { concentrated, } \\
\text { when demand is } \\
\text { increasing } \\
\text { /decreasing, etc. }\end{array}$ & $\begin{array}{l}\text { may not be } \\
\text { feasible for } \\
\text { areas with high } \\
\text { demand or } \\
\text { little tolerance } \\
\text { for interruption } \\
\text { of power }\end{array}$ & $\begin{array}{l}5-20 \%^{g} \\
12 \%^{h}\end{array}$ \\
\hline $\begin{array}{l}\text { Reactive power } \\
\text { compensation / } \\
\text { power factor } \\
\text { improvement (also } \\
\text { provides voltage } \\
\text { regulation and } \\
\text { control) }\end{array}$ & $\begin{array}{l}\text { can effectively } \\
\text { reduce the line } \\
\text { current, } \\
\text { eliminates } \\
\text { reactive power } \\
\text { circulation } \\
\text { from } \\
\text { generation } \\
\text { busses to load } \\
\text { busses }\end{array}$ & none & none & none & $30 \%{ }^{c}$ \\
\hline $\begin{array}{l}\text { Increase Voltage } \\
\text { Class }\end{array}$ & $\begin{array}{l}\text { implemented } \\
\text { flexibly, one } \\
\text { component at } \\
\text { a time; enables } \\
\text { voltage } \\
\text { increase } \\
\text { without } \\
\text { distorting } \\
\text { power quality }\end{array}$ & $\begin{array}{l}\text { modular } \\
\text { component } \\
\text { replacement } \\
\text { costs may } \\
\text { outweigh } \\
\text { system redesign } \\
\text { costs }\end{array}$ & $\begin{array}{l}\text { which } \\
\text { components } \\
\text { should be } \\
\text { replaced in what } \\
\text { order and with } \\
\text { what upgrades }\end{array}$ & none & $40-75 \%^{i}$ \\
\hline
\end{tabular}


${ }^{a}$ This column represents the estimates of potential distribution loss reductions within the specific kind of losses for each proposed strategy. It does not represent an estimate for what proportion of the total distribution losses that could be reduced in the U.S. using these strategies. Hence, these percentages should not be directly compared with one another, as the potential for loss reduction varies by loss type.

${ }^{b}$ EPRI, "Assessment of Transmission and Distribution Losses in New York State," November 2012.

${ }^{c}$ J. Weikert, "The Why of Voltage Optimization," Tech Surveillance, Cooperative Research Network, January 2013.

${ }^{d}$ S. Pande and J. G. Ghodekar, "Reduction of power loss of distribution system by distribution network management," International Journal of Multidisciplinary Sciences and Engineering, vol. 3, no. 11, November 2012.

${ }^{e}$ H. B. Tolabi , M. Gandomkar and M. B. Borujeni, "Reconfiguration and Load Balancing By Software Simulation in A Real Distribution Network for Loss Reduction," Canadian Journal on Electrical and Electronics Engineering, 2(8), Aug. 2011.

${ }^{f}$ R. D. Zimmerman, "Network Reconfiguration for Loss Reduction in Three-Phase Power Distribution Systems," Cornell University, 1992.

${ }^{g}$ Northwest Energy Efficiency Alliance (NEEA), "Distribution Efficiency Study,” 2007. Available at: http://tdworld.com/overhead_distribution/distribution-system-efficiency-20100201/.

${ }^{h}$ Dickson K. Chembe, "Reduction of power losses using phase load balancing method in power networks," in Proc., World Congress on Emerging and Computer Science, October 2009, San Francisco, CA.

${ }^{i}$ Based on the fact that the amount of ohmic (heat) loss is inversely proportional to the square of the voltage. 


\section{REFERENCES}

[1] The World Bank. "Electric power transmission and distribution losses (\% of output)," http://data.worldbank.org/indicator/EG.ELC.LOSS.ZS (accessed on 8/27/2014)

[2] Pabla, A.S., Electric Power Distribution, McGraw-Hill, New York, NY, 2005, pp. 287 and 291.

[3] Pilotto, L., "Enhancement of transmission capability," NSF/EPRI Workshop on Urgent Opportunities for Transmission System Enhancement, Palo Alto, October 2001.

[4] Kannberg, L. D., Chassin, D. P., DeSteese, J. G., Hauser, S. G., Kintner-Meyer, M. C., Pratt, R. G., \& Warwick, W. M. (2004). GridWiseTM: The benefits of a transformed energy system. arXiv preprint nlin/0409035.

[5] U.S. Energy Information Administration. 2014. State Electricity Profiles 2012. http://www.eia.gov/tools/faqs/faq.cfm?id=105\&t=3

[6] Thrash, R, Hudson, G., Cooper, D. and Sanders, G. 1994. Overhead Conductor Manual, Southwire Company, GA.

[7] Douglass, D. 2001. "The Objectives of Ampacity Uprating (Attractive Conductor Parameters for Reconductoring Existing Lines)." Proceedings of IEEE Power Engineering Society Summer Meeting, 2001, vol. 1, pp.169-174.

[8] Thrash, Jr., F.R. 2001. "ACSS/TW - An Improved High Temperature Conductor for Upgrading Existing Lines for New Construction," Proceedings of IEEE Power Engineering Society Summer Meeting, 2001, vol. 1, pp.182-185.

[9] Thrash, Jr., F.R. 2014. "Transmission Conductors - A Review of the Design and Selection Criteria," Technical Support Article, Southwire Company.

(http://www.southwire.com/support/TransmissionConductoraReviewOfTheDesignandSelectionCrite ria.htm (accessed on 9/8/2014)

[10] U.S. Department of Energy, Office of Electricity, Superconductivity for Electric Systems Annual Peer Review Meeting, presentations available online: http://www.superpowerinc.com/content/technical-documents, July 2008, Arlington, VA.

[11] The Economist 2001. "At last! The first practical superconducting power cables are now being installed." http://www.economist.com/node/691254.

[12] Wood, A.J. and Wollenberg, B.F. Power Generation Operation and Control, Wiley and Sons, New York, NY 2005.

[13] Jangjit, S., P. Kumkratug, and P. Laohachai. "Reduction of transmission line loss by using Interline Power Flow Controllers." In Electrical Engineering/Electronics Computer Telecommunications and Information Technology (ECTI-CON), 2010 International Conference on, pp. 450-453. IEEE, 2010.

[14] Paserba, J.J. 2004. "How FACTS controllers benefit AC transmission systems," Proceedings of IEEE Power Engineering Society General Meeting, 2004. Vol. 2, pp.1257-1262.

[15] Fandi, Ghaeth, Zdenek Muller, Libor Straka, and Jan Svec. "FACTS devices influence on power losses in transmission systems." In Electric Power Engineering (EPE), Proceedings of the 2014 15th International Scientific Conference, pp. 29-33. IEEE, 2014.

[16] Divan, D. and Johal, H. "Distributed FACTS - A new concept for realizing grid power flow control," IEEE Transactions on Power Electronics, vol. 22, no. 6, pp. 2253-2260, November 2007.

[17] Potluri, T. and Hedman, K.W., "Impacts of topology control on the ACOPF," Power and Energy Society General Meeting, 2012 IEEE, pp. 1-7, July 2012.

[18] Hedman, K.W., S.S. Oren, and R.P. O'Neill. 2011. "A review of transmission switching and network topology optimization," Proceedings of 2011 IEEE Power and Energy Society General Meeting, pp.1-7.

[19] Texas A\&M, Robust Adaptive Topology Control, http://smartgridcenter.tamu.edu/ratc/ (accessed on 9/8/2014).

[20] Hileman Insulation Coordination for Power Systems, Andrew R. Hileman, CRC Press, Taylor and Francis Group, Boca Raton, FL, 1999. See page 10 for a list of nominal/maximum system voltages. 
[21] Gallet, G., Leroy, G., Lacey, R., Kromer, I., "General Expression for Positive Switching Impulse Strength Valid Up to Extra Long Air Gaps," IEEE Trans. Power Apparatus and Systems, Vol. PAS94, No. 6, Nov./Dec. pp. 1989-1993, 1975.

[22] Menemenlis, C. and Harbec, G. Particularities of Air Insulation Behavior, IEEE Transactions on Power Apparatus and Systems, Vol PAS-95, No 6, Nov/Dec, pp 1814-1822, $1976 .$.

[23] Blue Book: "EHV Transmission Line Reference Book," Edison Electric Institute, 1968

[24] EPRI Red Book: "Transmission Line Reference Book: $345 \mathrm{kV}$ and Above," published in 1975 by EPRI, the Electric Power Research Institute. Generally known as the Red Book

[25] Thrash, Jr., F.R. 2014. "Transmission Conductors - A Review of the Design and Selection Criteria," Technical Support Article, Southwire Company.

(http://www.southwire.com/support/TransmissionConductoraReviewOfTheDesignandSelectionCrite ria.htm accessed on 9/8/2014)

[26] C. P. Steinmetz, "Transient Electric Phenomena and Oscillations," pp. 361-393, 1909/1920.

[27] Dwight, H.B. 1916. "Skin Effect of a Return Circuit of Two Adjacent Strap Conductors," The Electric Journal, April, p.157.

[28] Dwight, H.B. 1923. "Proximity Effect in Wires and Thin Tubes", Trans. A. I. E. E., 42: 850-859.

[29] Lu, F. C., You, S. H., Liu, Y. P., Wan, Q. F., \& Zhao, Z. B. (2012). “AC conductors' corona-loss calculation and analysis in corona cage." Power Delivery, IEEE Transactions on, 27(2), 877-885.

[30] Kirkham, H., "Analysis of multi-terminal HVDC systems," presentation for the Consortium for Electric Reliability Technology Solutions, DOE/OE Transmission Reliability Program, June 2013, Washington, DC.

[31] Westerweller, T., Friedrich, K., Armonies, U., Orinia, A., Parquet, D., \& Wehn, S. (2010). Trans bay cable - world's first HVDC system using multilevel voltage-sourced converter. CIGRE B4_101_2010. CIGRE.

[32] Dorn, J., Huang, H., \& Retzmann, D. (2008). A new Multilevel Voltage-Sourced Converter Topology for HVDC Applications. CIGRE B4-304. CIGRE.

[33] Asplund, G., Eriksson, K., Jiang, H.-B., Lindberg, J., Palsson, R., \& Svensson, K. (1998). DC Chinthavali, M., Tolbert, L. M., \& Ozpineci, B. (2004, June). SiC GTO thyristor model for HVDC interface. In Power Engineering Society General Meeting, 2004. IEEE (pp. 680-685). IEEE. transmission based on voltage source converters. CIGRE 14-302. CIGRE

[34] Chinthavali, M., Tolbert, L. M., \& Ozpineci, B. (2004, June). SiC GTO thyristor model for HVDC interface. In Power Engineering Society General Meeting, 2004. IEEE (pp. 680-685). IEEE.

[35] Assessment of Transmission and Distribution Losses in New York. EPRI, Palo Alto, CA: 2012. PID071178 (NYSERDA 15464).

[36] ABB, "Energy Efficiency in the Power Grid," Corporate Communication, 2007.

[37] Piercy, R. and Cress, S. L. "2007, Recalculation of Distribution System Energy Losses at Hydro One,” Kinectrics Inc., Report No: K-013111-001-RA-0001-R01, July 2007.

[38] Public Service Commission of Wisconsin, "Underground Electric Transmission Lines," May 2011.

[39] Eteruddin, H. and bin Mohd Zin, A.A. "Reduced Dielectric Losses for Underground Cable Distribution Systems," International Journal of Applied Power Engineering, vol. 1, no.1, pg. 37-46, Apr. 2012.

[40] Arnold, A.H.M., Electrical Engineers, Journal of the Institution of Volume: 67, Issue: 384 Issue: 384 DOI:10.1049/jiee-1.1928.0194, Publication Year: 1928, Page(s): 69 - 89

[41] Bakshi; Electrical Power Transmission and Distribution, Bakshi, U.A. and Bakshi, M.V. Technical Publications, Pune, India, 2007, ISBN 9788184312713

[42] Department of Energy-Building Technologies Program. Technical Support Document: Energy Efficiency Program For Commercial And Industrial Equipment: Electrical Distribution Transformers. September, 2007. Washington, DC: U.S. Department of Energy. http://www.eere.energy.gov/buildings/appliance_standards/commercial/distribution_transformers_fr _tsd.html 
[43] Li, D., Zhang, L., Li, G., Lu, Z., Zhou, S. "Reducing the core loss of amorphous cores for distribution transformers," Progress in Natural Science: Materials International, pg. 244-249, 2012.

[44] Borge-Diez, D., Colmenar-Santos, A., Castro-Gil, M. and Carpio-Ibáñez, J. "Parallel distribution transformer loss reductions: a proposed method and experimental validation," ELSEVIER Electrical Power and Energy Systems, vol. 49, pg. 170-180, 2013.

[45] Kefalas, T. D. and Kladas, A. G. "Harmonic Impact on Distribution Transformer No-Load Loss," IEEE Trans. On Industrial Electronics, vol. 57, no. 1, pg. 193-200, Jan. 2010.

[46] Getson, D. "Energy Efficiency Cost of Losses" ABB Presentation, May 20, 2013.

[47] Ferguson, G.N.C. and Damnjonovic, A. "The Measurement \& Evaluation of Distribution Transformer Losses under Non-Linear Loading," Power Quality International White Paper.

[48] Kirkham, H., Johnston, A., and Friend, H., Distribution Automation Applications of Fiber Optics, JPL Publication 89-10, Jet Propulsion Laboratory, January 1989, re-released as 89-10A, October 2008.

[49] EPRI, "Distribution system loss evaluation, reduction, technical and economic assessment," Report ID: 1016096, December 2008.

[50] Broadwater, R.P., Khan, A.H., Shaalan, H.E., Lee, R.E., Time varying load analysis to reduce distribution losses through reconfiguration, Power Delivery, IEEE Transactions on, Volume: 8, Issue: 1, DOI: 10.1109/61.180349, Publication Year: 1993, Page(s): 294 - 300, Cited by: Papers (42) Patents (1),

[51] GDS Associates, “Act 129 Demand response study," Final report, prepared for the Pennsylvania Public Utility Commission, May 2013.

[52] Basso, T. (2014). IEEE 1547 and 2030 Standards for Distributed Energy Resources Interconnection and Interoperability with the Electricity Grid (No. NREL/TP-5D00-63157). National Renewable Energy Laboratory (NREL), Golden, CO.

[53] Inan, H., Batson, J., and Scheibe, M., "Systems loss reduction," TechAdvantage, March 2014, available online: http://www.techadvantage.org/wp-content/uploads/2014/03/7B_Inan-andScheibe.pdf (accessed February 2015)

[54] Raminfard, A., Shahrtash, S.M., and Koshkhoo, H., Long-term Load Balancing Program in LV Distribution Networks, IEEE International Power Engineering and Optimization Conference, 2012

[55] Pinney, D. "Costs and Benefits of Conservation Voltage Reduction: CVR Warrants Careful Examination," NRECA-DOE Smart Gird Demonstration Project, Nov. 15, 2013.

[56] IEEE 1459: IEEE Standard Definitions for the Measurement of Electric Power Quantities Under Sinusoidal, Nonsinusoidal, Balanced, or Unbalanced Conditions, 2010

[57] National Electrical Manufacturers Association (NEMA), NEMA C12.24 TR-2011, Definitions for Calculations of VA, VAh, VAR, and VARh for Poly-Phase Electricity Meters. Technical Report prepared by NEMA and registered with ANSI, May 29, 2011

[58] EPRI, Power Quality for Transmission and Distribution: Harmonics Design and Analytics Guidebook, EPRI Report 1021736, November 2011.

[59] Eaton, "Power factor correction: a guide for the plant engineer," Aug. 2014.

[60] U. S. Department of Energy, "2014 Smart Gird System Report” Report to Congress, Aug. 2014.

[61] Schneider, K. P., Tuffner, F. K., Fuller, J. C. and Singh, R. "Evaluation of Conservation Voltage Reduction (CVR) on a National Level, "Pacific Northwest National Lab, Jul. 2010.

[62] Vidhyalakshmi, K., Zubair, S., Ramprasath, S., "Power Quality Improvement at the Distribution Side by the Use of Grid Interfaced Inverter," International Journal of Engineering and Advanced Technology, vol. 3, is. 2, pg. 103-109.

[63] EPRI and SAIC, "Assessment of Transmission and Distribution Losses in New York States." Report prepared for the New York State Energy Research and Development Authority, November 2012.

[64] ABB, "NYISO Transmission System Losses Exploration Study." April 82009.

[65] Litvinov, Zheng, Rosenwald and Shamsollahi. "Marginal Loss Modeling in LMP Calculation." IEEE Transactions on Power Systems, vol 19, no 2, May 2004. 
[66] Deilami, Masoum, Moses and Masoum. "Real-Time Coordination of Plug-In Electric Charging in Smart Grids to Minimize Power and Improve Voltage Profile." IEEE Transactions on Power Systems, vol 2, no 3, September 2011.

[67] Griffin, Tomsovic, Secrest and Law. "Placement of Dispersed Generations Systems for Reduced Losses." Proceedings of the $33^{\text {rd }}$ Hawaii International Conference on System Sciences - 2000.

[68] Song, Jung, Kim, Yun, Choi, and Ahn. "Operation Schemes of Smart Distribution Networks with Distributed Energy Resources for Loss Reduction and Service Restoration." IEEE Trans on Smart Grid, vol 4 no 1, March 2013.

[69] Rural Utilities Service, Guide for the Evaluation of Large Power Transformer Losses, RUS Bulletin 1724E-301, 2009.

[70] Berrisford, A.J., Smart Meters should be smarter, Power and Energy society General Meeting, 2012 IEEE, DOI: 10.1109/PESGM 2012.6345146, Publication Year. 2012, Page(s): 1 - 6, Cited by Papers (1)

[71] Win et al : "Constant DC Capacitor Voltage Control Based Strategy for Active Load Balancer in Three-phase Four-wire Distribution System” by Win, T.S., Hiraki, E., Okamoto, M., Lee, S.R. and Tanaka, T. IEEE International Conference on Electrical Machines and Systems

[72] EPRI, EPRI Smart Grid Demonstration Initiative, 4 Year Update, product ID 1025781, July 19, 2012.

[73] Kang, M.; Enjeti, P.N.; Pitel, I.J., Analysis and design of electronic transformers for electric power distribution system. Industry Applications Conference, 1997. Thirty-Second IAS Annual Meeting, IAS '97, Conference Record of the 1997 IEEE, Volume: 2, DOI:10.1109/IAS.1997.629077, Publication Year: 1997, Page(s): 1689 - 1694, vol.2

[74] PJM. "A Survey of Transmission Cost Allocation Issues, Methods and Practices." March 10, 2010.

[75] Navigant Consulting, Inc. "Transmission Planning White Paper." Report for EISPC and NARUC, Funded by the U.S. Department of Energy. January 2014.

[76] Electric Energy Institute. "State Generation \& Transmission Siting Directory." October 2013.

[77] DOE. "National Transmission Grid Study. Issue Papers: Transmission Siting and Permitting." May 2002.

[78] Council of State Governments." Interstate Compacts as a Policy Option to Enhance the Electric Transmission Line Siting Process.” February 2012.

[79] EPRI. "Demonstration of Advanced Conductors for Overhead Transmission Lines." Report prepared for the California Energy Commission. July 2008.

[80] Downs, Annie, and Celia Cui. "Energy Efficiency Resource Standards: A New Progress Report on State Experience.” American Council for an Energy-Efficiency Economic Report Number U1403, April 2014.

[81] EPRI, "Transmission Efficiency Technology Assessment.” EPRI Report, December 2009

[82] PNNL. "Evaluation of Conservation Voltage Reduction (CVR) on a National Level." PNNL-19596, July 2010.

[83] The Association of Electrical Equipment Manufacturers, "Volt/VAr Optimization Improves Grid Efficiency," NEMA Report, 2013.

[84] Weikert, J., "The Why of Voltage Optimization," Tech Surveillance, Cooperative Research Network, January 2013

[85] Su, C. T., \& Lee, C. S. (2001). Feeder reconfiguration and capacitor setting for loss reduction of distribution systems. Electric power systems research, 58(2), 97-102.

[86] Rugthaicharoencheep, N., \& Sirisumrannukul, S. (2009). Feeder reconfiguration for loss reduction in distribution system with distributed generators by tabu search. GMSARN International Journal, 3, 47-54.

[87] Zhang, et al. "Joint Optimization for Power Loss Reduction in Distribution Systems." IEEE Transactions on Power Systems, vol 23, No 1, February 2008.

[88] Aman et al. "Optimum shunt capacitor placement in distribution system - A review and comparative study." Renewable and Sustainable Energy Reviews 30 (2014) p. 429-439. 
[89] EPRI, (2011) Green Circuits: Distribution Efficiency Case Studies Report. Report \# 1023518 available at http://www.epri.com/abstracts/Pages/ProductAbstract.aspx?ProductId=000000000001023518.

[90] Energeia. "Energy Efficiency Opportunities in Electricity Networks: Findings of industry trials for the extension of the EEO Program to network businesses." Report prepared in consultation with the Australian Department of Resources, Energy and Tourism, May 2013. 


\section{APPENDIX A.}

\section{AUSTRALIAN NATION-WIDE STUDY}

Australia conducted an extensive analysis of loss reduction possibility in 2013. Although these findings should not be assumed to represent what would be feasible for the U.S. system, in the absence of a USspecific study, some general insight may be extracted from the Australian analysis [90]. Australia, like the U.S., has long transmission lines and diverse regional climates.

- The Australian analysis examined existing losses in the transmission and distribution systems, and presented estimates for savings potential. Transmission losses, ranging from $1.1 \%$ to $2.9 \%$ of total electricity produced, were found to come primarily from conductors and transformers. Distribution losses ranged from $3.7 \%$ to $9.1 \%$ of electricity produced. The existing equipment was generally highly efficient, although there was some potential for improving efficiency of distribution and transmission transformers. Total potential economic loss-reduction opportunities was calculated as 20 or $21 \mathrm{GWh}$ (depending on how losses were valued), at a cost of \$1.3 million (Australian dollars) per year. $^{26}$

Table A-1: Indicative potential electricity transmission loss reductions in Australia

\begin{tabular}{|c|c|c|c|c|c|c|}
\hline \multirow{4}{*}{$\begin{array}{l}\text { Network subsector } \\
\text { or activity }\end{array}$} & \multirow{4}{*}{$\begin{array}{l}\text { Losses } \\
\text { in } \\
\text { sector }\end{array}$} & \multicolumn{4}{|c|}{ Annual loss reduction potential } & \multirow[t]{4}{*}{ Notes } \\
\hline & & \multirow{3}{*}{$\begin{array}{l}\text { Losses } \\
\text { valued at } \\
\text { market cost } \\
\text { GWh }\end{array}$} & \multicolumn{2}{|c|}{ Losses valued at LRMC (a) } & \multirow{3}{*}{$\begin{array}{l}\text { Estimate of annual } \\
\text { capex to achieve } \\
\text { savings LRMC } \\
\text { Upper (b) } \\
\text { \$M }\end{array}$} & \\
\hline & & & Lower & Upper & & \\
\hline & & & GWh & GWh & & \\
\hline Transmission lines(b) & 5,000 & Nil & Not material & Not material & & (b) \\
\hline $\begin{array}{l}\text { Transmission } \\
\text { transformers }\end{array}$ & 7800 & Nil & 0.5 & 1 & 1.3 & (b) \\
\hline $\begin{array}{l}\text { Transmission } \\
\text { operations }\end{array}$ & & 20 & 20 & 20 & & (c) \\
\hline Total & $\begin{array}{l}\mathbf{5 , 8 0 0} \\
100 \%\end{array}$ & $\begin{array}{c}20 \\
0.3 \%\end{array}$ & $\begin{array}{c}20 \\
0.4 \%\end{array}$ & $\begin{array}{c}21 \\
0.4 \%\end{array}$ & 1.3 & (d) \\
\hline \multicolumn{7}{|c|}{$\begin{array}{l}\text { (a) The valuation of losses at their LRMC, including generation and network capital costs. An average valu } \\
\$ 110 / M W h \text { was assumed. } \\
\text { (b) Losses are already taken into account in the planning for this sector. } \\
\text { (c) AEMO advises there would be a software development cost to optimise the voltage profile but there } \\
\text { (d) Excludes AEMO cost. }\end{array}$} \\
\hline
\end{tabular}

Source: Ref. [90] p. 14

In the Australian study, more opportunity for savings existed at the distribution level since distribution losses are greater than that of the transmission. This is due to the fact that there are many distribution lines for each transmission line and the distribution system has lower voltage rating to distribute the power to the end users. In addition, at distribution level, many interconnects, various transformers at different voltage ratings, disconnect switches, breakers, connectors, and all the other connection and protection equipment results in higher losses. Analysis found the potential for reducing existing losses by 0.2 to

\footnotetext{
${ }^{26}$ The approximate exchange rate between Australian and U.S. dollars in 2013 was roughly 1 to 0.97.
} 
$0.5 \%$, estimated to save $\$ 3$ to $\$ 5$ million (Australian dollars). This savings is expected to come from many small, but economically-justified, investments on the distribution system, and is valued at the longrun marginal cost rather than current market prices. Long-run marginal costs take into account capacity costs of incremental transmission, distribution and generation in addition to the cost of power production. Particular strategies contributing to this savings estimate (along with estimates of loss and cost savings in millions of Australian dollars) include: procuring and installing more efficient transformers at the subtransmission/zone level ( 2 to 5\%; \$2M); load rebalancing, system augmentation or reconductoring at the high voltage distribution level (1.5 to 5\% loss savings; $\$ 24 \mathrm{M})$; reconductoring at the low voltage distribution level (1.5 to $5 \%$; $\$ 27 \mathrm{M})$; power factor correction by installing capacitor banks $(12 \% ; \$ 18 \mathrm{M})$. Overall, the estimate for economic loss-reduction opportunities in distribution networks was 0.2 to $0.5 \%$, or $16 \mathrm{GWh}$ to $46 \mathrm{GWh}$, at a cost of $\$ 77 \mathrm{M}$ (Australian dollars) per year to achieve the higher savings value.

Table A-2: Indicative potential loss reductions in electricity distribution networks in Australia

\begin{tabular}{|c|c|c|c|c|c|c|}
\hline \multirow{4}{*}{$\begin{array}{l}\text { Network subsector or } \\
\text { activity }\end{array}$} & \multirow{4}{*}{$\begin{array}{l}\text { Losses } \\
\text { in } \\
\text { sector }\end{array}$} & \multicolumn{4}{|c|}{ Annual loss reduction potential } & \multirow[t]{4}{*}{ Notes } \\
\hline & & \multirow{3}{*}{$\begin{array}{c}\begin{array}{c}\text { Losses } \\
\text { valued at } \\
\text { market cost }\end{array} \\
\text { GWh }\end{array}$} & \multicolumn{2}{|c|}{ Losses valued at LRMC (a) } & \multirow{3}{*}{$\begin{array}{l}\text { Estimate of annual } \\
\text { capex to achieve } \\
\text { savings LRMC } \\
\text { upper (b) } \\
\text { \$M }\end{array}$} & \\
\hline & & & Lower & Upper & & \\
\hline & & & GWh & GWh & & \\
\hline $\begin{array}{l}\text { Sub-transmission } \\
\text { network }\end{array}$ & 1,600 & Nil & Not material & $\begin{array}{c}\text { Not } \\
\text { material }\end{array}$ & & (c) \\
\hline $\begin{array}{l}\text { Sub-transmission/zone } \\
\text { transformers }\end{array}$ & 800 & Nil & 0.8 & 1.6 & 2 & \\
\hline $\begin{array}{l}\text { HV distribution } \\
\text { network }\end{array}$ & 2,200 & 6.6 & 10.9 & 14.6 & 24 & \\
\hline $\begin{array}{l}\text { Distribution } \\
\text { transformers }\end{array}$ & 2,800 & Nil & 1.1 & 2.9 & 5 & \\
\hline $\begin{array}{l}\text { Distribution } \\
\text { transformer MEPS }\end{array}$ & & 0.1 & 0.1 & 0.1 & N/A & (d) \\
\hline LV network & 1,900 & 5.6 & 9.4 & 12.5 & 27 & \\
\hline $\begin{array}{l}\text { Power factor } \\
\text { correction - DNSP }\end{array}$ & & Not material & 11.1 & 11.1 & 18 & \\
\hline $\begin{array}{l}\text { Power factor } \\
\text { correction - tariffs }\end{array}$ & & 3.7 & 3.7 & 3.7 & N/A & \\
\hline Demand management & & Not material & & & 0 & (e) \\
\hline Operational measures & & Not material & & & 0 & \\
\hline \multirow[t]{2}{*}{ Total (f) } & 9,300 & 16 & 37 & 46 & 77 & \\
\hline & $100 \%$ & $0.2 \%$ & $0.4 \%$ & $0.5 \%$ & & \\
\hline \multicolumn{7}{|c|}{$\begin{array}{l}\text { (a) The valuation of losses at their LRMC, including generation and network capital costs. The weighted } \\
\text { average value across the potential loss reductions is } \$ 153 / \mathrm{MWh} \text {. } \\
\text { (b) Assumes DNSP in effect pre-purchases the loss saving by incorporating the cost into each investment } \\
\text { decision. } \\
\text { (c) Losses are already taken into account in the planning for this sector and are very small relative to capital } \\
\text { costs. } \\
\text { (d) Distribution transformer minimum energy performance standards would specify a minimum efficiency, } \\
\text { and so is independent of how losses are valued. } \\
\text { (e) Assumes carried out to increase network capacity so utilisation is restored to former or higher levels. } \\
\text { (f) Total may not appear to reconcile due to rounding. }\end{array}$} \\
\hline
\end{tabular}

Source: Ref. [80] p. 15 
